\title{
Markedness and Laziness in Spanish Obstruents ${ }^{*}$ \\ Carlos-Eduardo Piñeros \\ University of Iowa
}

Cross-linguistic studies have shown that while there are languages whose sound inventories have an abundant number of voiced obstruents (e.g. English), there are others that are completely deprived of them (e.g. Hawaiian). By including voiced obstruents in its inventory, the former type of language has the possibility of encoding different meanings through the use of minimal pairs that contrast in voicing. Yet there are also languages, which have voiced obstruents but only of a certain type. In Spanish for example, fricatives and affricates do not contrast in voicing. Only stops may be voiced. Interestingly, Spanish not only restricts the type of obstruent that may be voiced; it also exhibits a tendency to minimize the use of the few voiced obstruents it has by alternating them with related sounds.

This paper studies the processes of spirantization and devoicing in Spanish. The analysis developed here relates these processes to the universal principles responsible for the limited number of voiced obstruents in this language. It also demonstrates that neither of these processes is an instance of feature spreading (assimilation). The actual aim in spirantizing or devoicing voiced stops is to simplify linguistic structures and gain articulatory ease. Voiced obstruents are marked at the phonological level, and effortful at the phonetic level, because they require intense muscular effort to sustain vocal fold vibration at the same time that an oral closure takes place. Although Spanish chooses to exploit voicing to create distinctive contrasts, it also resorts to strategies such as spirantization and devoicing to minimize the phonological markedness and articulatory 
cost that comes with imposing voicing on obstruent sounds. This approach assumes that phonetics and phonology are both part of the sound component of the grammar, and that certain sound patterns (e.g. categorial phenomena) are governed by the phonology, whereas others (e.g. gradient phenomena) are determined by the phonetics.

1. Inventory and distribution of Spanish obstruents

The obstruent class of the Spanish sound inventory is composed of stops, fricatives, and affricates. Among these subclasses, the presence of voicing creates an asymmetry between stops, on the one hand, and fricatives and affricates, on the other hand. As the following chart shows, fricatives and affricates do not have voiced counterparts ${ }^{1}$

\section{Spanish obstruent phonemes}

Labial Coronal Dorsal

\begin{tabular}{|c|c|c|c|}
\hline Stop & $\mathrm{p}$ & $\mathrm{t}$ & $\mathrm{k}$ \\
\hline Fricative & $\mathrm{f}$ & $\mathrm{s}$ & $\mathrm{X}$ \\
\hline
\end{tabular}

Although Spanish includes some voiced obstruent phonemes in its inventory, the stricture and voicing of these segments are often altered in the process of implementing them. Through spirantization, the voiced stops /b, d, g/ loosen their constriction to different degrees. Phonetic studies such as Quilis (1981) have found that Spanish voiced stops may surface as spirants with various degrees of constriction. These allophones are not limited to regular fricative articulations (e.g. $\beta, ð, \gamma]$ ), but range from articulations 
that involve a near complete oral closure (e.g. close fricatives: $[\beta, ð, \gamma]$ ), to articulations involving a degree of aperture quite close to vocalization (e.g. approximants: $\left.\left[\beta_{\tau}, \underset{\tau}{\not{\gamma}} \underset{\tau}{\gamma}\right]\right)^{2}$ Quilis (1981:224) points out that whereas fricatives have areas of resonance located in the upper half of the spectrum, the areas of resonance exhibited by approximants are located in the lower half. He reports that the high degree of aperture that characterizes approximants shows up in the sonograms as well-defined areas of resonance between the second and the third formants of any adjacent vowels. These findings have been corroborated by subsequent studies such as Martínez Celdrán (1984), who notes that approximants exhibit a degree of aperture that is greater than the aperture of any of the fricatives but lesser than the aperture of any vocoid. Approximants are articulated not only with a lesser degree of constriction than fricatives, but also with considerably lower tension and shorter duration, which makes them sound like a slight modification of any adjacent vowels (Martínez Celdrán 1984:170). Taking these phonetic findings into account, it seems inaccurate to continue to describe Spanish spirantization as a process that yields plain fricative sounds. It should be explained why close fricatives and approximants may result from this process as well.

It is also important to note that spirantization is a property of running, connected speech. At very slow speed, as when talking to a foreigner who has little competence in the language, spirantization is very unlikely to arise. But at very fast speed, as when talking to friends in a casual situation, spirantization occurs profusely. Furthermore, even at the same speed, dialects differ considerably in regards to the contexts where spirantization applies. In all dialects, at moderate speed, spirantization regularly fails to apply when the voiced stop is preceded by a nasal consonant, and it normally applies 
when the voiced stop is preceded by a vowel. However, there is a great deal of crossdialectal variation when the target sounds appear in other environments. In dialects where the application of spirantization is quite general, voiced stops spirantize not only when preceded by a vowel but also when preceded by consonants such $[\mathrm{r}],[1],[\mathrm{s}]$, or even by one of the consonants derived from spirantization. There are dialects where voiced stops spirantize even after a pause and, as reported by Hualde (1990), after a voiceless stop. Although spirantization has been reported to occur in all of these contexts, not all of them promote spirantization to the same extent. Amastae (1995) has demonstrated that even within dialects where spirantization applies after vowels and consonants, the probability that it will actually occur is greater if the voiced stop is preceded by a vowel and decreases gradually if preceded by a glide, rhotic, lateral or obstruent consonant. It has also been noticed that in dialects where spirantization applies after consonants, /d/ often resists spirantization if the preceding segment is [1], although in the same dialects $/ \mathrm{b} /$ and $/ \mathrm{g} /$ regularly spirantize in this context. To sum up, Spanish dialects range from very restricted spirantization, which is limited to post-vocalic position, to very general spirantization, which may occur even after a pause or a voiceless stop.

Rather than tackling all dialects and speed rates at once, I start by focusing on the distribution of voiced stops within a single dialect at moderate speed. The dialect selected is Panamanian Spanish, described in detail by Alvarado de Ricord (1971). In this dialect, spirantization is neither too restricted nor too general. As in all Spanish dialects, voiced stops in Panamanian Spanish normally undergo spirantization when preceded by a vowel, (2a). Spirantization also applies after glides, (2b), the glottal 
segment [h] (derived from underlying /s/), (2c), and liquid consonants, $(2 \mathrm{~d}, \mathrm{e})$. By contrast, voiced stops regularly fail to spirantize when preceded by a spirant, (2f), nasal consonant, $(2 \mathrm{~g})$, voiceless stop, $(2 \mathrm{~h})$, or a pause, $(2 \mathrm{i})$. It is also important to point out that the asymmetry between /d/ and the other two voiced stops observed in other Spanish dialects when these segments are preceded by [1], also holds in Panamanian Spanish. To simplify the exposition, during the first part of the paper, I will abstract away from the fact that spirants surface with different degrees of constriction. The symbols $[B, D, G]$ will be used to represent the output of spirantization regardless of whether the spirant is a close fricative, fricative or approximant. As the key factors that undermine the stricture of voiced stops are revealed (Section 7), the distinction between the different types of spirant will be made explicit.

\section{Spirantization of voiced stops in Panamanian Spanish at moderate speed}

Context

a. Vowel

\begin{abstract}
a
\end{abstract}
b. Glide

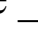
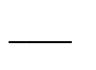

c. $\mathrm{h}$

$\sqrt{2}$

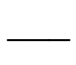

d. Rhotic

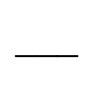

e. Lateral

$-$

\section{Labial}

1[i.B]ro

'book'

Coronal

Dorsal

$\mathrm{k}[\mathrm{o.D}] \mathrm{o}$

'elbow'

1[a.G]o

le[in.B]a

'last name'

'debt'

de[h.D]e

'desde'

be[r.D]e

'green'

sa[1.d] $]$ o

'balance' 'lake'

$\operatorname{tra}[\mathrm{i} . \mathrm{G}] \mathrm{o}$

'I bring'

$\mathrm{mu}[\mathrm{h} . \mathrm{G}] \mathrm{o}$

'moss'

la[r.G]o

'long'

sa[1.G]o

'I leave' 
f. Spirant

$$
\begin{aligned}
& \text { a[D.b]erso } \\
& \text { 'adverse' }
\end{aligned}
$$

a[B.d]dikar

e[D.g]ar

g. Nasal

'abdicate'

'proper name'

h. Stop

so[m.b]ra

$\mathrm{o}[\mathrm{n} \cdot \mathrm{d}] \mathrm{a}$

sa[y.g]re

'shadow'

'wave'

'blood'

fu[t.b]ol

eda[t.d] $]$ eoro

pare[t.g]rande

'football'

'golden age'

'big wall'

i. Pause

[b]ueno

$[\mathrm{d}]$ ose

[g]ano

'good'

'twelve'

'I win'

In addition to spirantization, Spanish voiced stops are affected by processes of devoicing and voicing assimilation, which very from one dialect to another (Martínez-Gil 1992). In Panamanian Spanish, voiced stops are subject to devoicing when they are assigned to syllable-final position (Alvarado de Ricord 1971). As a consequence of this process, the distinction between voiced and voiceless stops is neutralized syllable finally. However, because a voiced stop in syllable-final position is always preceded by a vowel, spirantization may also apply in this context.

\begin{tabular}{|c|c|c|c|}
\hline $\begin{array}{l}\text { Labial } \\
\text { absuelto }\end{array}$ & [p.] [B.] & $\begin{array}{l}\text { Coronal } \\
\text { birtud }\end{array}$ & {$[\mathrm{t}.] \sim[\mathrm{D}]$.} \\
\hline 'absolved' & & 'virtue' & \\
\hline subomarino & {$[\mathrm{p}.] \sim[\mathrm{B}]$.} & siudad & {$[\mathrm{t}.] \sim[\mathrm{D}]$.} \\
\hline 'submarine' & & 'city' & \\
\hline obtener & [p. $] \sim[$ B. $]$ & sed & {$[\mathrm{t}.] \sim[\mathrm{D}]$.} \\
\hline 'to obtain' & & 'thirst' & \\
\hline
\end{tabular}

(3) Devoicing/spirantization of voiced stops syllable finally 
c. Dorsal

\begin{tabular}{|c|c|}
\hline dogma & {$[\mathrm{k}.] \sim[\mathrm{G}]$.} \\
\hline \multicolumn{2}{|c|}{ 'dogma' } \\
\hline pugna & {$[\mathrm{k}.] \sim[\mathrm{G}]$.} \\
\hline 'fight' & \\
\hline signo & {$[\mathrm{k}.] \sim[\mathrm{G}]$.} \\
\hline
\end{tabular}

The data in (3) show that, in coda position, voiced stops may be realized in two different ways. They may surface either as voiceless stops or as spirants. That is to say that in this structural role, voiced stops must either lose their voicing or reduce the degree of their stricture. Speakers of Panamanian Spanish pronounce these words either way. In order to explain these patterns, I argue below that devoicing and spirantization are optimal strategies to deal with voiced stops because by undermining the vibratory state the vocal folds (devoicing), or the degree of oral constriction (spirantization), these processes directly tackle the structural complexity and physiological difficulty that arises from forcing voicing on stops.

\section{Phonetics and Phonology}

In the previous section I have noted that the outcome of spirantization is gradient (e.g. various degrees of stricture), and that the application of this process depends on speech rate and register as well as the phonetic context where the voiced stop is found. This means that a full account of this process may not be completely abstract, but must be connected to these factors, which pertain to the phonetics. Following work by 
Pierrehumbert (1980), Keating (1985), and Hayes (1996), I assume that the grammar has both a phonological and a phonetic component. In other words, the phonetics is not external, but actually a part of the grammar. On this view, some of the sound patterns of a language are determined in the phonology; others however, are decided by the phonetics.

Based on phonetic evidence from different languages, Keating (1985) concludes that patterns of phonetic detail must be part of the grammar because they are not automatic or universal, but actually controlled by each language. Hayes (1996) also observes that although phonetics and phonology control the sound system of the grammar, there are clear distinctions between them. Phonetics is asymmetrical, and it involves gradient and variable phenomena. Phonology, on the other hand, is symmetrical, categorial, and far less variable. Another distinction is that prosodic constituents such as syllables, feet and prosodic words play a key role in the phonology, but have no weight in the phonetics. To observe these facts, I assume a model suggested by Hayes (1996), in which the phonology generates surface phonological representations from abstract ones, and the phonetics then derives physical forms from the surface representations generated by the phonology.

(4) Sound component of the grammar (After Hayes 1996)

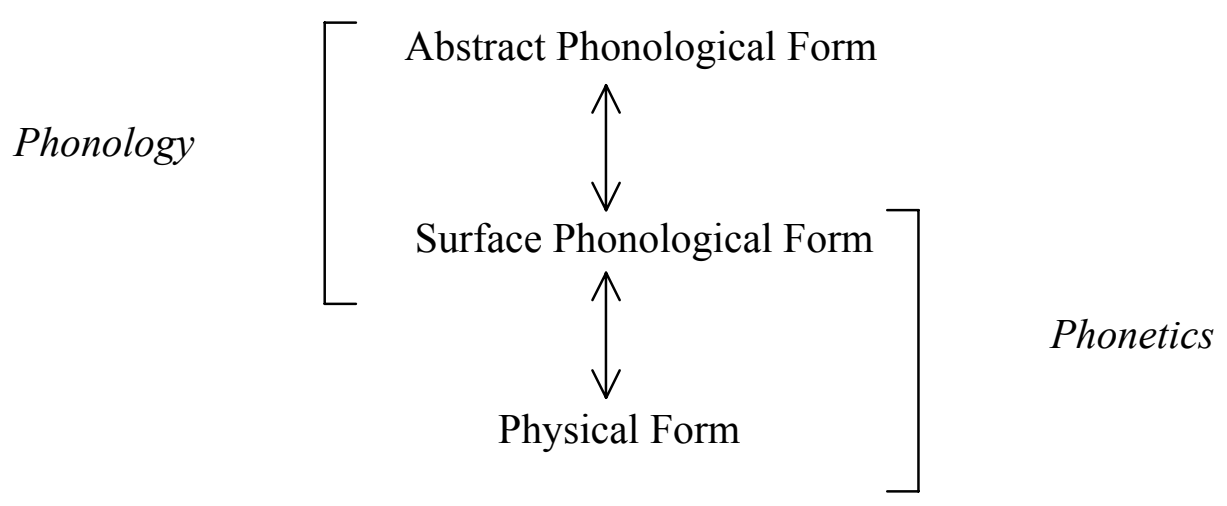


It is also assumed that both sub-components are Optimality-theoretic and that their markedness constraints are grounded. That is to say that all markedness constraints must be based on physical factors that cause certain articulations to be more costly than others. On this view, phonology is phonetically natural because the constraints it includes are the product of grammar design carried out unconsciously, but intelligently (Hayes 1996). This is possible because the two subcomponents are connected. However, whereas phonology thrives to maintain distinctive contrasts (favors faithfulness), phonetics leans towards articulatory ease (favors markedness). Markedness constraints originate in the phonetics but may be elevated to the phonology where they can block faithfulness constraints. Faithfulness constraints originate in the phonology, but they may also be enforced in the phonetics to the point that they may block the drive to achieve articulatory ease (Keating and Westbury 1986).

\section{Markedness in obstruents}

It is a well-known phonetic fact that voicing is not an inherent property of obstruent sounds. Phoneticians have observed that whereas in the articulation of sonorants vocal fold vibration comes rather effortlessly, voiced obstruents require additional muscular effort in order to get the vocal folds to vibrate (van den Berg 1958, Lisker and Abramson 1971, Ohala 1983, Henton, Ladefoged and Maddieson 1991). This is due to the fact that vocal fold vibration is an aerodynamic event, which in addition to a light adduction of the vocal folds requires air flowing through the glottis from areas of high to low pressure. Nevertheless, in sounds articulated with a high degree of oral constriction, air pressure builds up in the oral cavity. High pressure above the larynx 
disrupts the high-to-low-pressure system required for air to flow through the glottis. As air stops flowing through the glottis, the vocal folds stop vibrating and voicing dies out. These articulatory events provide grounds to assume that voiced obstruents are marked sounds. Confirmation that the presence of vocal fold vibration adds to the markedness of obstruent segments is provided by the fact that sound inventories more often have voiceless obstruents than voiced ones (Maddieson 1984). Cross-linguistic studies have revealed that while languages that have voiced obstruents invariably also have a series of voiceless obstruents, the reverse of this is not true. The lesser frequency of voiced obstruents may be explained by positing a context-free markedness constraint prohibiting segments to contain the features [-sonorant] and [voice] (Beckman 1999).

$$
\begin{array}{ll}
\text { *VDOBStR: } & \text { Voiced obstruents are prohibited. }{ }^{3} \\
& *[\text {-sonorant, voice }]
\end{array}
$$

Maddieson (1984) also reports that whereas stops occur in the inventories of all known human languages, fricatives have been found absent from a small number of languages (mainly Australian languages), and although most languages include at least one fricative sound in their inventories, this type of obstruent occurs less profusely than stops. These remarks concord with Schmidt (1926:287) who claims that whereas there are languages that have stop consonants without their corresponding fricatives, there are no languages that have fricatives without their stop counterparts. Maddieson (1984:42) cites work by Hale (1976) who shows that in Australian languages, a language family where fricatives are often absent, these sounds have been developed from stops through a process of laxing. This latter observation dovetails with the fact that in the process of acquiring a language, children get to master fricative sounds only after they have already 
acquired the corresponding stops. For Spanish, Boyd-Bowman (1955:348) reports that /f/ is acquired after $/ \mathrm{p} /, / \mathrm{s} /$ after $/ \mathrm{t} /$, and $/ \mathrm{x} /$ after $/ \mathrm{k} /$. These facts about language acquisition and sound inventories suggest that fricatives are more marked than stops. Their greater markedness is due to the controlled nature of the gesture involved in producing their frication since it is required that the articulators be kept from reaching complete contact, nonetheless, a close approximation in order to yield high pressure and high air velocity is also required (Ohala 1983:201). To factor these facts into the phonology, I rely on the markedness constraint *FRICATIVE, which prohibits segments that combine the features [-sonorant] and [+continuant].

*FRICATIVE:

Fricatives are prohibited.

$$
\text { *[-sonorant, + continuant] }
$$

\section{Accounting for the Spanish obstruent inventory}

Within Optimality Theory, the sound inventory of a language is determined by the interaction of markedness and faithfulness constraints according to the ranking in which these two types of universal principles are organized in the grammar. Since the decision lies entirely on the constraint component of the grammar, input forms may be infinitely rich. According to Richness of the Base, "the grammatical inventories of a language are the outputs which emerge from the grammar when it is fed the universal set of all possible inputs." (Prince and Smolensky 1993:3). The assumption that all possible inputs may feed the grammar, forces us to consider that the Spanish segments that sometimes surface as $[\mathrm{b}, \mathrm{d}, \mathrm{g}]$ may originate from segments other than $/ \mathrm{b}, \mathrm{d}, \mathrm{g} /$. This approach keeps us from stipulating what the input should be. The actual input is selected through 
constraint interaction. In the case at hand, the relevant markedness constraint is *VDOBSTR, which antagonizes with the faithfulness constraint that promotes the preservation of voicing specifications, (7). Given that Spanish does include some voiced obstruents in its sound inventory, *VDOBSTR must be dominated by the faithfulness constraint.

(7) FAITH(voice): $\quad$ Correspondent segments must agree in voicing.

Under the ranking FAITH(voice) $>$ *VDOBSTR, if an input segment bears the feature [voice], its output correspondent must bear that specification as well, (8a). In fact, the output correspondents of underlying obstruents that do not bear this feature must also abstain from acquiring it. However, although both voiced and voiceless obstruents must have faithful correspondents under this ranking, the preservation of voiceless obstruents is always less costly because they do not run afoul of the markedness constraint, $\left(8 b^{\prime}\right)$. This is a reflection of the fact that voicelessness is an inherent property of obstruents.

$$
\text { FAITH(voice) }>>* \text { VDOBSTR }
$$

\begin{tabular}{cc||c|c}
\multicolumn{2}{l||}{ Input: /b, d, g/ } & FAITH(voice) & *VDOBSTR \\
\hline \hline a. $\quad \mathrm{b}, \mathrm{d}, \mathrm{g}$ & & $* * *$ \\
\hline $\mathrm{b} . \quad \mathrm{p}, \mathrm{t}, \mathrm{k}$ & $* * * !$ & \\
\hline \hline Input: $/ \mathrm{p}, \mathrm{t}, \mathrm{k} /$ & & \\
\hline \hline $\mathrm{a} ! \quad \mathrm{b}, \mathrm{d}, \mathrm{g}$ & $* * * !$ & \\
\hline $\mathrm{b} ! \quad \mathrm{p}, \mathrm{t}, \mathrm{k}$ & & \\
\hline
\end{tabular}


It is precisely because of their lower cost that languages more often use voiceless obstruents than voiced ones. Spanish, however, opts to pay the higher cost of having voiced obstruents in order to use voicing contrasts to encode different meanings (e.g. paso 'step' $\sim$ baso 'glass'). It is to be faithful to such contrasts that $[\mathrm{b}, \mathrm{d}, \mathrm{g}]$ are preserved in output forms. Given that being faithful to an underlying voicing specification is more highly valued than having to make additional effort to yield voicing in these segments, $/ \mathrm{b}, \mathrm{d}, \mathrm{g} /$ must be the input correspondents of $[\mathrm{b}, \mathrm{d}, \mathrm{g}]$ in this grammar. This is determined by the principle of Lexicon Optimization (Prince and Smolensky 1993), which states that of a set of possible inputs, the actual input is the one that represents the most harmonic mapping from input to output. To evaluate the possible inputs, a tableau des tableaux is presented in (9). This is a device within Optimality Theory that allows us to compare the attested output with the set of possible inputs in order to select the optimal input. Under the ranking FAITH(voice) $>$ *VDOBSTR, the segments $/ b, d, g /$ are the optimal input for the allophones $[b, d, g]$ because they avoid falling in violation of the dominant faithfulness constraint, (9a).

(9) Selection of the optimal input

\begin{tabular}{|c|c|c|c|c|c|c|}
\hline \multicolumn{3}{|r|}{ Inputs } & \multicolumn{2}{|r|}{ Output } & \multirow[t]{2}{*}{ FAITH(voice) } & \multirow{2}{*}{$\frac{* \text { VDOBSTR }}{* * *}$} \\
\hline$\infty$ & a. & $/ \mathrm{b}, \mathrm{d}, \mathrm{g} /$ & & a. $\quad b, d, g$ & & \\
\hline & & $/ \mathrm{p}, \mathrm{t}, \mathrm{k} /$ & $\oplus$ & b. $\quad b, d, g$ & $* * * !$ & $* * *$ \\
\hline
\end{tabular}

The reversal of this ranking constitutes another type of language in which voiced stops may never surface. The following tableau shows that no matter if one posits voiced stops in the input, the dominant markedness constraint will force them to lose their 
voicing, (10b). Voiceless obstruents are always able to surface because they do not run afoul of the markedness constraint, $\left(10 b^{\prime}\right)$.

*VDOBSTR $\gg$ FAITH(voice)

\begin{tabular}{cc||c|c}
\multicolumn{2}{c||}{ Input: $/ \mathrm{b}, \mathrm{d}, \mathrm{g} /$} & $*$ VDOBSTR & FAITH(voice) \\
\hline $\mathrm{a} . \quad \mathrm{b}, \mathrm{d}, \mathrm{g}$ & $* * * !$ & \\
\hline $\mathrm{b} . \quad \mathrm{p}, \mathrm{t}, \mathrm{k}$ & & $* * *$ \\
\hline \hline Input: $/ \mathrm{p}, \mathrm{t}, \mathrm{k} /$ & & \\
\hline \hline $\mathrm{a} ! \mathrm{b}, \mathrm{d}, \mathrm{g}$ & $* * * !$ & $* * *$ \\
\hline $\mathrm{b}^{\prime} . \quad \mathrm{p}, \mathrm{t}, \mathrm{k}$ & &
\end{tabular}

In this grammar, the optimal inputs for surface $[\mathrm{p}, \mathrm{t}, \mathrm{k}]$ are underlying $/ \mathrm{p}, \mathrm{t}, \mathrm{k} /$, (11b). This is because since the dominant markedness constraint never allows voiced stops to surface, the speakers of this language do not have empirical evidence that would allow them to posit underlying voiced obstruents. A language representative of this type of grammar is Hawaiian, where obstruents may only be voiceless (Maddieson 1984, Beckman 1999).

(11) Selection of the optimal input

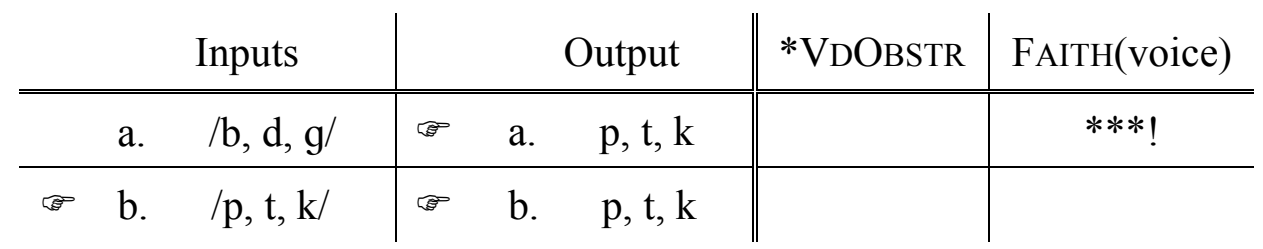

In sum, grammars with the ranking *VDOBSTR $>$ FAITH(voice) do not have voiced obstruents, whereas grammars with the ranking FAITH(voice) $>>*$ VDOBSTR allow them. Obviously, Spanish belongs to the second class. However, the ranking 
FAITH(voice) $>>*$ VDOBSTR does not adequately account for the obstruent inventory of this language. The problem with this ranking is that it predicts the existence of more obstruent sounds than Spanish actually has. In particular, since Spanish has the set of voiceless fricatives [f, $\mathrm{s}, \mathrm{x}]$, one would also expect this language to have the set of voiced fricatives $[v, z, \gamma]$. This follows from the fact that the voiced fricatives $/ v, z, \gamma /$ are possible inputs that would be faithfully mapped onto the output correspondents $[v, z, \gamma]$ given the ranking FAITH(voice) $>>$ VDOBSTR. The same argument applies to affricates: $/ \check{y} /$ is a possible input that would be faithfully mapped onto a surface voiced affricate [y̌]. Tableau (12) illustrates this problem.

$$
\text { FAITH(voice) }>\text { VDDOBSTR }
$$

\begin{tabular}{|c|c|c|c|c|}
\hline \multicolumn{3}{|c|}{ Input: $/ \mathrm{v}, \mathrm{z}, \gamma, \check{\mathrm{y}} /$} & \multirow{2}{*}{$\begin{array}{c}\text { FAITH(voice) } \\
* * * * !\end{array}$} & \multirow[t]{2}{*}{ *VDOBSTR } \\
\hline & a. & $f, s, x, c ̌ c$ & & \\
\hline 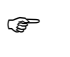 & b. & $\mathrm{v}, \mathrm{z}, \gamma, \mathrm{y}$ & & $* * * *$ \\
\hline \multicolumn{5}{|c|}{ Input: /f, s, x, č/ } \\
\hline$\Phi$ & $a^{\prime}$. & $f, s, x, \check{c}$ & & \\
\hline & $b^{\prime}$. & $v, z, \gamma, \check{y}$ & $* * * * !$ & $* * * *$ \\
\hline
\end{tabular}

The voicing contrasts that result from the evaluations in (12) are the wrong result for Spanish because this language does not have minimal pairs of voiced and voiceless fricatives or affricates. Only stops contrast in voicing. I propose to account for this asymmetry between Spanish stops and fricatives/affricates through the markedness constraint *VDCONTOBSTR, (13), which is grounded on the fact that voicing is aerodynamically incompatible with frication. As Ohala (1983:201) has remarked, voiced 
fricatives are challenging from an aerodynamic point of view because in order to yield their voicing, oral pressure must be low; yet in order to yield their frication, oral pressure must be high. 'Meeting both of these requirements may be difficult. To the extent that the segment retains voicing it may be less of a fricative, and if it is a good fricative it runs the risk of being devoiced'. The incompatibility between these two properties, which crucially define voiced fricatives as a class, makes these segments more costly.

*VDCONTOBSTR: Voiced continuant obstruents are prohibited. *[-sonorant, +continuant, voice]

Both fricatives and affricates run afoul of this constraint because they are obstruent segments that implement the feature [+continuant]. The ranking *VDCONTOBSTR $>$ FAITH(voice) $>$ *VDOBSTR successfully accounts for the Spanish obstruent inventory as illustrated in tableau (14). Whether input fricatives/affricates are voiced or voiceless, their optimal correspondents must be voiceless in order to avoid running afoul of *VDCONTOBSTR, (14a \& 14a').

*VDCONTOBSTR $>>$ FAITH(voice) $>>$ *VDOBSTR

\begin{tabular}{|c|c|c|c|c|}
\hline \multicolumn{2}{|c|}{ Input: $/ \mathrm{v}, \mathrm{z}, \gamma, \mathrm{j} /$} & \multirow[t]{2}{*}{ *VDCONTOBSTR } & \multirow{2}{*}{$\frac{\text { FAITH(voice) }}{* * * *}$} & \multirow[t]{2}{*}{ *VDOBSTR } \\
\hline a. & $\mathrm{f}, \mathrm{s}, \mathrm{x}, \check{\mathrm{c}}$ & & & \\
\hline b. & $\mathrm{v}, \mathrm{z}, \mathrm{\gamma}, \mathrm{j}$ & $* * * * !$ & & $* * * *$ \\
\hline \multicolumn{5}{|c|}{ Input: /f, s, x, č/ } \\
\hline$\approx a^{\prime}$. & $\mathrm{f}, \mathrm{s}, \mathrm{x}, \check{\mathrm{c}}$ & & & \\
\hline$b^{\prime}$. & $\mathrm{v}, \mathrm{z}, \mathrm{\gamma}, \mathrm{j}$ & $* * * * !$ & $* * * *$ & $* * * *$ \\
\hline
\end{tabular}


Of the two logical possibilities illustrated in (14), the actual input correspondents for surface $[f, s, x, \check{c}]$ are /f, s, x, č/ because they represent the most transparent mapping, as the following tableau des tableaux illustrates, (15a).

Selection of the optimal input

\begin{tabular}{c|cc||c|c|c}
\multicolumn{2}{c|}{ Inputs } & Output & $\begin{array}{c}* \text { VDCONT } \\
\text { OBSTR }\end{array}$ & FAITH(voice) & $*$ VDOBSTR \\
\hline \hline a. $\quad / \mathrm{f}, \mathrm{s}, \mathrm{x}, \check{\mathrm{c}} /$ & a. $\mathrm{f}, \mathrm{s}, \mathrm{x}, \check{\mathrm{c}}$ & & & \\
\hline b. $/ \mathrm{v}, \mathrm{z}, \mathrm{r}, \check{\mathrm{y}} /$ & & b. $\mathrm{f}, \mathrm{s}, \mathrm{x}, \check{\mathrm{c}}$ & & $* * * !$ &
\end{tabular}

Summing up, Spanish lacks voiced fricatives/affricates because the markedness constraint *VDCONTOBSTR outranks the faithfulness constraint FAITH(voice). This ranking diminishes the repertoire of voicing contrasts that Spanish may use to encode meanings (cf. English, which obeys the reversal of this ranking). However, Spanish does have voicing contrasts among stops because FAITH(voice) dominates *VDOBSTR. This ranking provides the language with the possibility of encoding different meanings by alternating between $/ \mathrm{p}, \mathrm{t}, \mathrm{k} /$ and $/ \mathrm{b}, \mathrm{d}, \mathrm{g} /$. Nevertheless, although the language wants to have the possibility of encoding different meanings through this contrast, voiced stops are always costly. This cost stems from physiological limitations that give rise to a conflict between the mechanism that produces voicing and the presence of a high degree of constriction in the oral cavity. Because obstruents have the highest degrees of consonantal constriction, voicing may not arise in these segments unless active adjustments, which require additional muscular effort, are made. In the next sections, I show that Spanish resorts to the processes of devoicing and spirantization in order to minimize the complexity of these segments and the effort required to articulate them. 
5. Featural unfaithfulness as markedness reduction

The fact that voiced stops always devoice or spirantize in syllable-final position, whereas this is not always the case in syllable-initial position, indicates that faithfulness to the syllable onset is more highly valued.

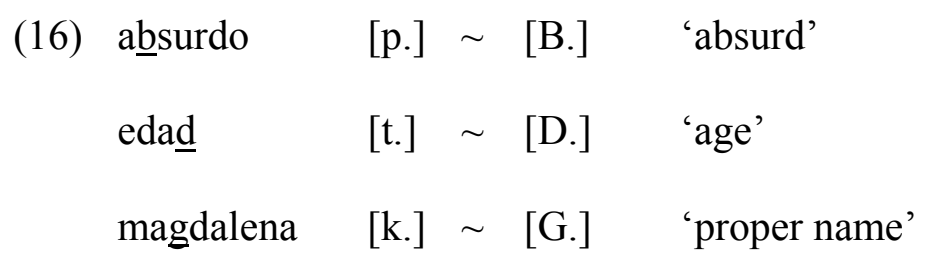

Beckman (1996, 1999) proposes to capture the privileged status of certain linguistic positions through positional faithfulness constraints, which are universally ranked above context-free faithfulness constraints: FAITH-Position $>$ FAITH. This proposal is based on the assumption that prominent positions require greater faithfulness. Within the syllable domain, for example, onsets are perceptually more prominent by virtue of their release, which serves to signal a wider range of distinctive contrasts. The prominence of syllable onsets results in greater faithfulness to onset segments: FAITHONSET > FAITH. The positional faithfulness constraints that are relevant to our discussion are FAITH-ONSET(voice) and FAITH-ONSET(stricture), defined as follows.

(17) FAITH-OnSET(voice): Onset segments and their input correspondents must agree in voicing.

(18) FAITH-ONSET(strict): Onset segments and their input correspondents must agree in stricture. 
It was concluded in the previous section that Spanish has voiced stops because FAITH(voice) dominates *VDOBSTR. Although basically true, this ranking is imprecise because the voicing of an underlying voiced stop may be lost when parsed as a syllable coda. In other words, when the correspondent of an input segment is parsed in a nonprominent syllabic position, it may be coerced to be unfaithful by losing its voicing. This indicates that although FAITH-ONSET(voice) dominates *VDOBSTR, the markedness constraint dominates the context-free faithfulness constraint. Furthermore, because in syllable-final position all stops may spirantize, whereas in syllable-initial position this is not always the case, it must be that *VDOBSTR also dominates FAITH(strict), but it is dominated by FAITH-OnSET(strict). ${ }^{4}$ Because they are specific versions of the same principle, I combine the two positional faithfulness constraints in a single constraint ranked above *VDOBSTR. For the same reason, I combine the two context-free faithfulness constraints in a single one ranked below *VDOBSTR.

FAITH-ONSET(voice, strict) $>>$ *VDOBSTR $>$ FAITH(voice, strict)

\begin{tabular}{ccc|c|c|c}
\multicolumn{2}{c|}{ Input: } & birtud/ & $\begin{array}{c}\text { FAITH-ONSET } \\
\text { (voice, strict) }\end{array}$ & $*$ VDOBSTR & $\begin{array}{c}\text { FAITH } \\
\text { (voice, strict) }\end{array}$ \\
\hline \hline a. & bir.tud & & $* * !$ & \\
\hline b. & bir.tut & & $*$ & $*$ \\
\hline & c. & bir.tuD & & $*$ & $*$ \\
\hline d. & pir.tut & $* !$ & & $* *$ \\
\hline e. & Bir.tuD & $* !$ & & $* *$
\end{tabular}

Candidates $(19 \mathrm{~d}, \mathrm{e})$ are ruled out by FAITH-ONSET(voice, strict) because the segments $[\mathrm{p}]$ and $[\mathrm{B}]$, which they parse as syllable onsets, do not accord in voicing with their input correspondents. Although candidate (19a) remains faithful to all segments 
that are parsed as syllable onsets, the next-ranking constraint, *VDOBSTR, favors (19b) and $(19 \mathrm{c})$ because they reduce the markedness of the output form by ridding an obstruent consonant of a feature that is marked and effortful to implement in this type of segment. These two candidates are equally optimal because they resort to the same strategy, which consists of finding a balance between the mandate to be faithful to the segments in prominent positions and the drive to avoid segments with non-inherent voicing. The segments [t] and [D] in the optimal output forms are allowed to disagree in voicing and stricture with their input correspondents because they are parsed in non-prominent positions, which does not concern the dominant constraint FAITH-ONSET(voice, strict). Although these are faithfulness violations, they are tolerated because they only upset the bottom-ranking constraint FAITH(voice, strict). Limiting the preservation of the feature voice only to segments that appear in prominent positions serves to yield less marked output forms, and thereby reduce the effort required to utter them. To promote unmarkedness beyond that, it would be necessary to lose the marked feature in prominent positions as well: *VDOBSTR $>$ FAITH-OnSET(voice, strict) >> FAITH(voice, strict). This, however, would abolish all contrast between voiced and voiceless stops, and it would make it impossible for voiced stops to ever arise, even in prominent positions. But since voiced and voiceless stops never neutralize syllable-initially and they do not always spirantize in that position, the ranking in (19) holds strong.

I conclude that syllable-final devoicing and spirantization are strategies used in the phonology of Panamanian Spanish to reconcile two conflicting forces. On the one hand, the language wants to have voicing contrasts to encode different meanings, and on the other hand, speakers want to minimize the markedness of linguistic forms, so that 
they may reduce the effort required to utter them. By suppressing the marked property only in non-prominent positions, the contrast is maintained in the system, while speakers are able to save energy since they only have to intensify effort in prominent positions. This explains the pattern exhibited by the data in (3). ${ }^{5}$

6. Previous accounts of Spanish spirantization

Most accounts of Spanish spirantization have analyzed this process as an instance of progressive assimilation. Assimilationist approaches may be divided into (i) those that rely on spreading of the feature [+continuant] (Harris 1984, Mascaró 1984), (ii) those that use spreading of the feature [-continuant] (Lozano 1979, Hualde 1988), and (iii) those that resort to an assimilatory constraint requiring adjacent output segments to agree in stricture (Gnanadesikan 1997, Piñeros 1999).

Within the first approach, a segment bearing the feature [+continuant] passes it on to a following voiced stop causing it to spirantize. Such analyses are challenged by the fact that in certain dialects the segment $/ 1 /$, which is [+continuant], does not cause spirantization of a following $/ \mathrm{d} /$, although it regularly induces spirantization in a following $/ \mathrm{b} /$ or $/ \mathrm{g} /$. Furthermore, there are dialects in which not all [+continuant] segments spread this feature to a following segment (e.g. dialects from Colombia, El Salvador, Honduras and Nicaragua, where spirantization is restricted to post-vocalic position). An even greater challenge these analyses have to face is the one posed by dialects where voiced stops spirantize even after a voiceless stop (e.g. Bone[t.G]a.no 'Bonet won', as reported by Hualde 1990). Since voiceless stops do not bear the feature 
[+continuant], it is not evident how spreading of this feature could be responsible for spirantization in this case.

The second type of assimilationist analysis, assumes underspecification of voiced stops for continuancy. A voiced stop preceded by a segment that bears the feature [-continuant] receives this specification through spreading provided that the two segments are homorganic. In the rest of environments, voiced stops are assigned the default specification [+continuant] by a feature-filling rule. These analyses are confronted by the fact that in some dialects [-continuant] nonhomorganic consonant clusters are indeed possible (e.g. Vietna[m.d]el Norte 'Northern Viet Nam', fu[t.b]ol 'football', Ma[g.d]alena 'proper name), which argues against the claim that the source of the [-continuant] specification of the voiced stop is a preceding homorganic segment. Dialects where utterance-initial voiced stops do not spirantize are also a problem for this approach because they are expected to surface as [+continuant] since they are not preceded by a [-continuant] homorganic segment that would supply them with this feature. Furthermore, the assumption that $[+$ continuant $]$ is the default specification for obstruent segments is at odds with the finding that stops are less marked than fricatives.

The last assimilationist approach to spirantization has been developed within Optimality Theory invoking a surface-identity constraint (e.g. AsSIM), which forces adjacent output segments to agree in feature specifications (Gnanadesikan 1997). Surface-identity states that segments that are adjacent in the output form participate in an identity relationship that drives them to resemble one another. From this standpoint, voiced stops spirantize when preceded by vowels, liquids and fricatives in order to have a degree of constriction that is more similar to the stricture of those segments. Dialects 
where spirantization only applies post-vocalically require the introduction of additional constraints to block ASSIM when the preceding segment is consonantal. Similarly, to account for the lack of spirantization of utterance-initial voiced stops, a positional faithfulness constraint would have to be invoked to override AssiM, but Gnanadesikan does not develop the analysis fully. Dialects where spirantization applies after stops are a major problem for this approach because in that case, spirantization renders two adjacent segments that were identical in stricture, non-identical. Furthermore, under the assumption that segments that are adjacent in the output form are driven to resemble one another in stricture, it becomes a total mystery why voiceless stops do not spirantize when preceded by the same segments that induce spirantization in voiced stops. Because they are identical in stricture to their voiced counterparts, voiceless stops should also spirantize when abutted by segments of lesser stricture.

7. Featural unfaithfulness as effort reduction

Kirchner $(1995,1998)$ and Widdison (1997) depart from the trend to account for spirantization as an assimilation process and opt to explore a different avenue. These authors take into account that for the vocal folds to vibrate at the same time that an oral closure takes place; muscular effort must be intensified to prevent voicing from dying out. This is because vocal fold vibration critically depends on air flowing through the glottis from areas of high to low pressure. An articulation with an oral closure causes the airflow to stop, which increases the pressure in the supralaryngeal cavity. High pressure above the larynx disrupts the high-to-low-pressure system required for air to flow through the glottis. As air stops flowing through the glottis, the vocal folds stop vibrating and 
voicing dies out. Ventilation through the nose serves to release supralaryngeal pressure, which reestablishes transglottal airflow. It is this possibility that yields the inherent voicing of nasal consonants despite the fact that they are articulated with complete oral closure. Alternatively, diminishing the degree of the oral closure also reduces supralaryngeal pressure and makes it easier to maintain the airflow necessary for the vocal folds to remain in motion. This is precisely the effect of spirantization. In changing from stop to fricative, and ultimately approximant, a segment reduces the degree of oral closure, which brings the oral pressure down and allows voicing to emerge at a lower effort cost. That is to say that the motivation that lies at the core of spirantization is not to promote agreement in stricture values among adjacent segments (assimilation), but actually a drive to reduce articulatory effort while maintaining the voicing of a segment that is originally intended to have complete oral closure. In Widdison's terms, spirantization is the result of 'target undershooting'. All these phonetic observations lead us to conclude that spirantization is caused by a principle of articulatory ease, rather than forced by feature spreading operations or assimilation constraints. Following this line of research, I proceed to develop an analysis of Spanish spirantization based on the effort-reduction constraint LAZY (Kirchner 1994, 1998), as defined below.

(20) LAZY: Reduce muscular effort in the articulation of segments.

My claim is that LAZY is not a phonological, but a phonetic constraint. It sanctions the effort required to articulate segments, not the complexity of linguistic structures. Note that although related, these two notions belong to two different levels. 
In articulating segments, muscles must be activated through neurological impulses that consume energy. It is at this level that LAZY works to promote effort savings. By contrast, although grounded on phonetic facts, markedness constraints such as *VDOBSTR operate at an abstract linguistic level where categorial, not gradient distinctions, are observed. To incorporate this proposal, a phonetic component endowed with its own constraint ranking must be allowed in the grammar, (see 4). At this low level, the structures prohibited by phonological markedness constraints may also be banned by principles of phonetic implementation, which come into conflict with the faithfulness constraints that require identity between the surface phonological form and the physical form. LAZY is one of such low-level linguistic principles.

To assess effort consumption, a continuum of effort thresholds is construed ranging from segments that require minimum effort to segments that demand maximum effort. For each effort threshold there is a LAZY constraint that penalizes the sounds that reach that threshold. Given that effortful segments are more costly, the constraints that militate against higher effort thresholds must be higher ranking than those that penalize lower effort thresholds. As an illustration, consider the case of voiced and voiceless stops, whose effort thresholds are prohibited by LAZY(Stop) and LAZY(VdStop).

(21) LAZY(Stop): $\quad$ Reduce muscular effort in the articulation of stops. "Do not reach effort threshold eff"

(22) LAZY(VdStop): Reduce muscular effort in the articulation of voiced stops. "Do not reach effort threshold eff +1 " 
By attributing to them the violation of a higher-ranking anti-effort constraint, this approach formally captures the fact that voiced stops are more effortful than voiceless ones. Note from tableau (23) below that whereas voiced stops violate the constraint LAZY(VdStop) and consequently, all other LAZY constraints that guard lower effort thresholds, (23b), voiceless stops always violate one LAZY constraint less because their effort threshold is not as high, (23a).

$$
\operatorname{LAZY}(e f f+1)>>\operatorname{LAZY}(e f f)>>\operatorname{LAZY}(e f f-1)
$$

\begin{tabular}{cc||c|c|c} 
& & $\begin{array}{c}\text { LAZY(VdStop) } \\
\text { eff }+1\end{array}$ & $\begin{array}{c}\text { LAZY(Stop) } \\
\text { eff }\end{array}$ & $\begin{array}{c}\text { LAZY(Other) } \\
\text { eff }-1\end{array}$ \\
\hline \hline a. $\quad \mathrm{p}, \mathrm{t}, \mathrm{k}$ & & $* * *$ & $* * *$ \\
\hline b. & $\mathrm{b}, \mathrm{d}, \mathrm{g}$ & $* * * !$ & $* * *$ & $* * *$
\end{tabular}

In order to estimate effort costs more precisely, Kirchner (1998) posits abstract effort units, which facilitate the task of comparing segments in terms of the amount of effort required to articulate them. As Kirchner stresses, it should be kept in mind that these effort units are not actual physical measurements, but estimates of relative effort based on articulatory events and factors such as displacement, impedance, precision, and velocity. By hypothesis, the total effort necessary to articulate a segment can be calculated by adding the efforts required to produce each one of its articulatory gestures. For the purpose of this paper, however, the only effort dimension that interests us is the one where the gestures for vocal fold vibration and stricture intersect.

Westbury (1983:1322) notes that for the vocal folds to vibrate, they must be properly adducted and tensed, and there must be sufficient transglottal pressure gradient for air to flow through the glottis. Although we know that these conditions require a rise 
in subglottal pressure initiated by the lungs as well as activity of the structures in the larynx, we do not know with precision all of the structures that are involved in these actions, much less can we measure with all accuracy the amount of effort spent in performing each one of them. Although precise effort measurements of all the structures that participate in the production of voicing are beyond our current capabilities, our understanding of the mechanism used to produce voicing allows us to identify conditions that favor vocal fold vibration, which make it less effortful, as well as factors that are detrimental to it and make voicing more effort-consuming. Based on the presence/absence of these factors, we can make estimates of how effortful it is to produce voicing in a segment.

Let us assume that the effort thresholds in (24) represent the amount of effort required to produce voiced segments in isolation. The rationale for assuming these values is as follows. Taking into account, that a complete oral closure is the highest impediment to voicing (van den Berg 1958, Lisker and Abramson 1971, Ohala 1983, Westbury 1983, Westbury and Keating 1986, Henton, Ladefoged and Maddieson 1992), I assume that in segments with maximal constriction, voicing is the most effortful; and conversely, in segments with little or no constriction at all, voicing is the least effortful. According to this, I estimate a threshold of 100 effort units for the production of voicing in stops. I have chosen to use a scale of 0-100 where the lowest value stands for no effort at all (lack of all gestures necessary to produce voicing), and the highest value is assigned to stops according to the rationale above. ${ }^{6}$ Voiced close fricatives are slightly less effortful (95 effort units) than stops because the articulators do not produce a tight seal, which amounts to slightly less oral pressure. Voiced fricatives have a wider opening, 
which causes less pressure to build up in the oral cavity; hence they do not offer as much resistance to voicing, (90 effort units). Voiced nasals are considerably less effortful (50 units) because a lowered velum releases supralaryngeal pressure, which promotes the pressure differential necessary for transglottal airflow (Henton, Ladefoged and Maddieson 1992). Likewise, by reducing the oral constriction, approximants avoid excessive build-up of oral pressure (Martínez Celdrán 1984), which I estimate alleviates the production of voicing as much as lowering the velum. Voicing in laterals (40 effort units) is more effortful than in rhotics (30 effort units) because they obstruct the airflow to a greater sub-degree by interposing a central contact round which air is obliged to flow (Laver 1994:306). Finally, glides (20 effort units) are also more effortful than vowels (10 effort units) because of their lesser degree of aperture.

Estimated effort thresholds for voiced segments in isolation

Segments

Voiced stops:

Voiced closed fricatives:

Voiced fricatives:

Voiced nasals:

Voiced approximants:

Voiced laterals:

Voiced rhotic:

Voiced glide

Voiced vowel b, d, g Effort threshold

100

95

90

50

50

40

30

$\stackrel{i}{i}, \underline{u}$

20

10 
Based on these estimates, it is possible to develop a universal hierarchy of antieffort constraints for voiced articulations, (25), which ranges from segments where voicing is minimally hindered by little or no constriction at all, to segments where voicing is seriously challenged by the presence of a high degree of oral constriction. ${ }^{7}$

\section{Universal effort hierarchy for voicing}

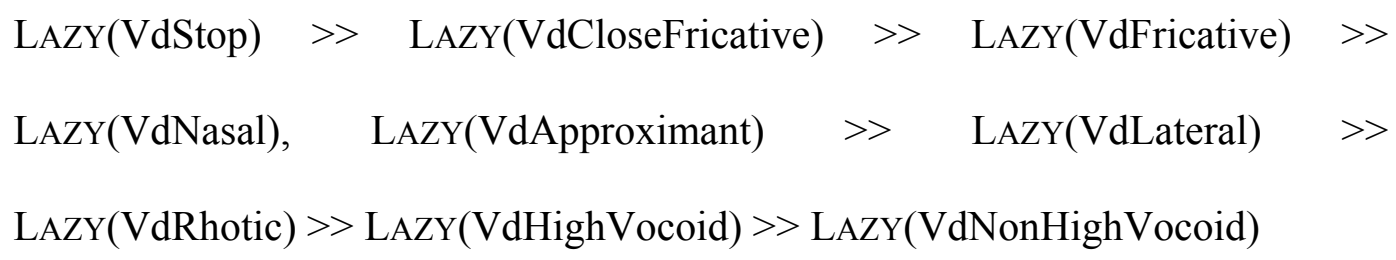

In addition to this universal hierarchy, one must also take into account that sounds are not produced in isolation and that the context in which they appear bears on the actual effort that their articulation requires. Because in running, connected speech, segments influence other segments in the speech signal, the quality of adjacent segments has important consequences for effort reduction. Following Laver (1994:112), I assume that the articulation of any segment has three phases: an onset phase, a medial phase, and an offset phase. The medial phase is the period during which the maximum closure/aperture is achieved. The onset phase embodies the approach of the vocal organs to the medial phase, whereas the offset phase consists of the movement of the organs towards the medial phase of the next segment, and hence constitutes an overlap phase with the onset phase of that next segment. In terms of stricture, if the medial phase of a segment requires an aperture gesture (e.g. /a/), and the medial phase of the following segment requires a closure gesture (e.g. /d/), then the active articulator has to cover a considerable distance during the overlap phase. By contrast, if the medial phases of two adjacent 
segments involve movements in the same direction (e.g. both involve closure or aperture), then the shorter distance that the active articulator has to travel from one target to the other makes it possible to save some effort. Consequently, the estimated 100 effort units necessary to produce a voiced stop in isolation are actually not all needed when the medial phase of the preceding segment already involves some degree of constriction. Since this constriction brings the active articulator closer to the target of the voiced stop, the displacement and effort necessary to produce the voiced stop are reduced.

By contrast, a constriction during the medial phase of a following segment may not contribute to reduce the effort in articulating the voiced stop because that gesture comes after all three phases of the voiced stop have already been completed. Note that this does not mean that the constriction/aperture of the medial phase of a following segment is irrelevant to reduce effort. Obviously, whenever less displacement is required, less effort needs to be consumed. However, while a following segment may contribute to reduce the total amount of effort invested in the syllable or larger constituents, it has no impact on the effort required to articulate a segment whose articulation has already been fully implemented. This is an inevitable consequence of the temporal organization of segmental units.

Let us assume that a preceding vowel makes no contribution to reducing the effort in producing the complete oral closure of a voiced stop because this kind of segment has no constriction at all. Glides, which are not as open as vowels, make a minor contribution (5 effort units). Rhotics (10 effort units) and laterals (15 effort units) increase their contributions because their medial phases involve increasing degrees of 
constriction. Likewise, approximants (20 effort units) and fricatives (25 effort units) further contribute to reduce the effort in achieving the complete oral closure of stops because their medial phases involve closer degrees of approximation. An even greater contribution is made by oral stops (30 effort units), whose complete closure during the medial phase considerably diminishes the magnitude of the displacement necessary to yield the complete closure of another stop. Nasals also have this effect, but they further reduce the effort necessary to articulate a following voiced stop because by lowering the velum they provide venting that facilitates voicing (35 effort units). Following Widdison (1997:78), I assume that a pause contributes as much as a stop consonant, considering that the resting position of the articulators often implies a closure of the vocal tract. Additionally, the possibility for two adjacent segments to have the exact same point of articulation allows a major reduction of articulatory effort (15 extra units) because in such case no displacement of the active articulator is necessary.

(26) Estimated effort contributions from neighboring segments to the articulation of voiced stops

\section{Segments}

Nasal stops:

Oral stops/Pause:

Fricatives:

Approximants:

Lateral:

Rhotic: $\mathrm{m}, \mathrm{n}, \mathrm{j}$

b, d, g, p, t, k

$\beta, ð, \gamma, \mathrm{f}, \mathrm{s}, \mathrm{x}$

$\beta_{\tau}, \underset{\sim}{\partial}, \underset{\tau}{\gamma}$

1

r
Effort contribution

35

30

25

20

15

10 

Glides
i, $\underline{n}$
05
Vowels
a, e, i, o, u
00
*Add 15 extra units for homorganicity

Factoring these environmental contributions into the calculation, we may conclude that the actual effort thresholds to produce voiced stops when preceded by other segments in running, connected speech are as in (27).

\begin{tabular}{|c|c|c|c|c|}
\hline Context & Stop in isolation & Context co & & Actual effort \\
\hline Nasal stop & 100 & 35 & $=$ & 65 \\
\hline Oral stop/Pause & 100 & 30 & $=$ & 70 \\
\hline Fricative & 100 & 25 & $=$ & 75 \\
\hline Approximant & 100 & 20 & $=$ & 80 \\
\hline Lateral & 100 & 15 & $=$ & 85 \\
\hline Rhotic & 100 & 10 & $=$ & 90 \\
\hline Glide & 100 & 05 & $=$ & 95 \\
\hline Vowel & 100 & 00 & $=$ & 100 \\
\hline
\end{tabular}

*Subtract 15 additional units for homorganicity

The chart above shows that the production of voiced stops is most effortful after a vowel (100 effort units), whereas it is significantly less so in the presence of a preceding nasal consonant ( 65 effort units, without place assimilation, but 50 when the nasal has become homorganic). With these results, it is not surprising that in all Spanish dialects 
spirantization is most likely to apply postvocalically, since it is there that voiced stops are especially effort consuming. Conversely, it is expected that voiced stops are the least likely to spirantize after nasal stops since these segments maximally facilitate the oral closure/voicing that voiced stops have to strive for.

Let us further assume that for each actual effort threshold in (27), there is an antieffort constraint in the phonetic component that penalizes all segments that reach that threshold. I will label these constraints $\operatorname{LAZY}_{100}$, LAZY 95 , LAZY $90, \operatorname{LAZY}_{85}, \operatorname{LAZY}_{80}$, LAZY $_{75}$, LAZY $_{70}$, and LAZY 65 Because higher effort thresholds are more difficult to achieve, the ranking among these constraints must be $\operatorname{LAZY}_{100} \gg \operatorname{LAZY}_{95} \gg>\operatorname{LAZY}_{90}$, and so on. By ranking logic, when all faithfulness constraints in the phonetic component dominate all anti-effort constraints, the surface phonological representation (the input to the phonetics), must be preserved intact regardless of how much effort is required to implement it. For spirantization to apply to those voiced stops that have survived in the surface phonological representation because of being in syllable-initial position, some anti-effort constraint(s) must outrank the positional, and by transitivity, the context free faithfulness constraints FAITH-ONSET(stricture) and FAITH(stricture). As a consequence of this, voiced stops must alter their stricture if their implementation requires reaching the relevant effort threshold. Given that both the positional and the context-free faithfulness constraints are dominated in the phonetic component, there is no need to distinguish between them here.

(28) FAITH(stricture): Correspondent segments must agree in stricture. 
In dialects whose phonetic component includes the ranking LAZY $_{100}>>$ FAITH(strict), spirantization has a chance to affect voiced stops but only in those contexts where yielding a voiced stop would require 100 effort units. This is exactly the most restricted type of spirantization attested in certain dialects (Canfield 1981), which draw the line in between vowels and glides. In tableau (29), spirantization is optimal if the voiced stop is preceded by a vowel, (29b), but not if it is preceded by a glide, (29c). The voiced stop may not be faithfully preserved postvocalically because avoiding an effort of 100 units is more important than retaining its complete oral closure, (29b). Of course, producing any of the spirant allophones also requires some effort but any of them involves a lower threshold (as low as 50 effort units, according to the estimates in (24) but less if the preceding segment has similar stricture). On the other hand, whenever the articulation of the voiced stop requires an effort of less than 100 units, which is anywhere except postvocalically, the constraint FAITH(strict) is able to force the preservation of its complete oral closure, (29c). To simplify the tableaux, the only violations of LAZY constraints that will be counted are those incurred by the correspondents of underlying voiced stops.

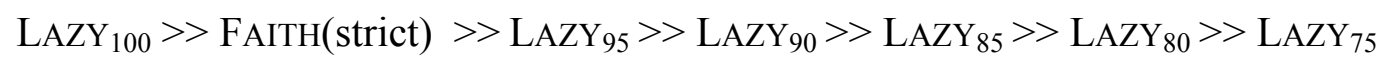

\begin{tabular}{|c|c|c|c|c|c|c|c|c|c|}
\hline & Input: /pago/ & $\begin{array}{c}\text { LAZY } \\
100\end{array}$ & $\begin{array}{l}\text { FAITH } \\
\text { (strict) }\end{array}$ & $\begin{array}{c}\text { LAZY } \\
95\end{array}$ & $\begin{array}{c}\text { LAZY } \\
90\end{array}$ & $\begin{array}{c}\text { LAZY } \\
85\end{array}$ & $\begin{array}{c}\text { LAZY } \\
80\end{array}$ & $\begin{array}{c}\text { LAZY } \\
75\end{array}$ & $\begin{array}{c}\text { LAZY } \\
70\end{array}$ \\
\hline & [pago] & $* !$ & & $*$ & $*$ & $*$ & $*$ & $*$ & $*$ \\
\hline$\infty$ & [paGo] & & $*$ & & & & & & \\
\hline \multicolumn{10}{|c|}{ Input: /kaigo/ } \\
\hline 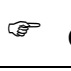 & kaigo & & & $*$ & $*$ & $*$ & $*$ & $*$ & $*$ \\
\hline & kaíno & & $* !$ & & & & & & \\
\hline
\end{tabular}


Yet other Spanish dialects, have allowed FAITH(strict) to be demoted even lower. When LAZY $_{95}$ is promoted above FAITH(strict), voiced stops spirantize after glides as well. This is a pattern identified in contemporary Bogotano Spanish by Amastae (1995:272), who found in his Bogotano informants that the probability that spirantization will apply after a vowel or glide is much greater than the probability that it will apply after liquids or other consonants, suggesting that Bogotano Spanish draws the line in between consonantal and non-consonantal segments.

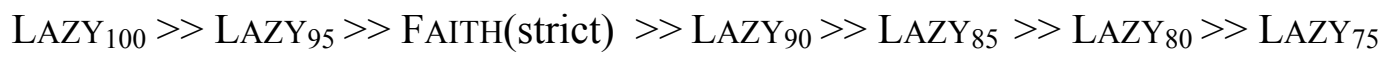

\begin{tabular}{c||c|c|c|c|c|c|c|c} 
Input: /kaigo/ & $\begin{array}{c}\text { LAZY } \\
100\end{array}$ & $\begin{array}{c}\text { LAZY } \\
95\end{array}$ & $\begin{array}{c}\text { FAITH } \\
\text { (strict) }\end{array}$ & $\begin{array}{c}\text { LAZY } \\
90\end{array}$ & $\begin{array}{c}\text { LAZY } \\
85\end{array}$ & $\begin{array}{c}\text { LAZY } \\
80\end{array}$ & $\begin{array}{c}\text { LAZY } \\
75\end{array}$ & $\begin{array}{c}\text { LAZY } \\
70\end{array}$ \\
\hline \hline a. kaigo & & $* !$ & & $*$ & $*$ & $*$ & $*$ & $*$ \\
\hline b. kaiGo & & & $*$ & & & & & \\
\hline \hline Input: /arbol/ & & & & & & & & \\
\hline \hline c. arbol & & & & $*$ & $*$ & $*$ & $*$ & $*$ \\
\hline d. arBol & & & $* !$ & & & & &
\end{tabular}

In tableau (30), spirantization is disfavored in post-consonantal position, because the effort thresholds required to produce voiced stops after consonants are lower ranking than the drive to remain faithful to the stricture of abstract segments, (30c). Because this drive is only surpassed by thresholds of 95 effort units and higher, spirantization is favored only after a non-consonantal segment, (30b).

Progressively, there are Spanish dialects where the probability that spirantization will apply after vocoids and liquid consonants is quite high, but considerably lower after approximants, fricatives or stops. Panamanian Spanish can be placed in this group. Recall that in Panamanian Spanish, spirantization also applies after [h], which is derived 
from an underlying $/ \mathrm{s} /$. This is to be expected given that $[\mathrm{h}]$ has no oral constriction and consequently, like vowels, this segment makes no contribution to reducing the distance that the active articulator has to travel to achieve the complete oral closure of a following voiced stop. When FAITH(strict) has been demoted below LAZY $_{85}$, the spirantization patterns exhibited by Panamanian Spanish arise.

$$
\operatorname{LAZY}_{100} \gg>\operatorname{LAZY}_{95}>>\operatorname{LAZY}_{90}>>\operatorname{LAZY}_{85}>>\text { FAITH}\left(\text { strict) }_{2}>\operatorname{LAZY}_{80}>>\operatorname{LAZY}_{75}\right.
$$

\begin{tabular}{c||c|c|c|c|c|c|c|c} 
Input: $/$ arbol/ & $\begin{array}{c}\text { LAZY } \\
100\end{array}$ & $\begin{array}{c}\text { LAZY } \\
95\end{array}$ & $\begin{array}{c}\text { LAZY } \\
90\end{array}$ & $\begin{array}{c}\text { LAZY } \\
85\end{array}$ & $\begin{array}{c}\text { FAITH } \\
\text { (strict) }\end{array}$ & $\begin{array}{c}\text { LAZY } \\
80\end{array}$ & $\begin{array}{c}\text { LAZY } \\
75\end{array}$ & $\begin{array}{c}\text { LAZY } \\
70\end{array}$ \\
\hline a. arbol & & & & $* !$ & & $*$ & $*$ & $*$ \\
\hline b. arBol & & & & & $*$ & & & \\
\hline Input: $/$ afgano/ & & & & & & & & \\
\hline \hline c. afgano & & & & & & & $*$ & $*$ \\
\hline d. afGano & & & & & $* !$ & & &
\end{tabular}

Under this ranking, spirantization is optimal when the preceding segment contributes 15 effort units or less because such contribution is not enough to reduce the actual effort below the point where losing the stricture of the underlying segment is too costly, (31b). On the other hand, when the preceding segment contributes more than 15 effort units, the actual effort to produce the voiced stop is reduced to a threshold that is not as highly valued, (31c).

The asymmetry observed in various dialects between the coronal voiced stop and the labial and dorsal ones, when preceded by a lateral segment, follows from the fact that Spanish laterals only assimilate in place of articulation to a following coronal consonant. As a consequence of this, the articulation of a coronal voiced stop in post-lateral position receives an extra 15-unit reduction that is not available to dorsal or labial stops. In tableau 
(32), spirantization is optimal after a lateral consonant when the voiced stop is either labial, (32b), or dorsal, (32f), because producing a voiced stop in such context requires 85 effort units, a threshold that ranks higher than featural faithfulness. By contrast, spirantization is disfavored if the voiced stop in post-lateral position is coronal, because for being homorganic with the preceding segment, its articulation requires 15 effort units less, a threshold that does not challenge featural faithfulness, (32c).

$$
\operatorname{LAZY}_{100} \gg>\operatorname{LAZY}_{95} \gg>\operatorname{LAZY}_{90}>>\operatorname{LAZY}_{85}>>\text { FAITH(strict) }_{2} \text { LAZY }_{80} \gg>\operatorname{LAZY}_{75}
$$

\begin{tabular}{c||c|c|c|c|c|c|c|c} 
Input: $/$ salgo/ & $\begin{array}{c}\text { LAZY } \\
100\end{array}$ & $\begin{array}{c}\text { LAZY } \\
95\end{array}$ & $\begin{array}{c}\text { LAZY } \\
90\end{array}$ & $\begin{array}{c}\text { LAZY } \\
85\end{array}$ & $\begin{array}{c}\text { FAITH } \\
\text { (strict) }\end{array}$ & $\begin{array}{c}\text { LAZY } \\
80\end{array}$ & $\begin{array}{c}\text { LAZY } \\
75\end{array}$ & $\begin{array}{c}\text { LAZY } \\
70\end{array}$ \\
\hline \hline a. salgo & & & & $* !$ & & $*$ & $*$ & $*$ \\
\hline b. salGo & & & & & $*$ & & & \\
\hline \hline Input: $/$ saldo/ & & & & & & & & \\
\hline c. saldo & & & & & & & & $*$ \\
\hline d. salDo & & & & & $* !$ & & & \\
\hline Input: $/$ salbo/ & & & & & & & & \\
\hline e. salbo & & & & $* !$ & & $*$ & $*$ & $*$ \\
\hline f. salBo & & & & & $*$ & & &
\end{tabular}

Dialects where spirantization applies after vocoids and consonants, except for oral and nasal stops, may be accounted for by demoting FAITH(strict) below LAZY 75 . Castilian Spanish (Navarro Tomás 1967) and Mexico City Spanish (Harris 1969) are dialects that exhibit this pattern. Tableau (33) shows that when the preceding segment contributes savings of 25 or less effort units, spirantization is optimal because in these dialects featural faithfulness ranks below the 75-unit effort threshold, (33b). By the same token, voiced stops do not spirantize if the preceding segment contributes more than 25 
effort units since this contribution makes it unnecessary to be unfaithful to the complete oral closure of the input voiced stop, (33c).

$$
\operatorname{LAZY}_{100} \gg>\operatorname{LAZY}_{95}>>\operatorname{LAZY}_{90}>\operatorname{LAZY}_{85}>\operatorname{LAZY}_{80} \gg \operatorname{LAZY}_{75}>>\text { FAITH(strict) }
$$

\begin{tabular}{c||c|c|c|c|c|c|c|c} 
Input: $/$ rasgo/ & $\begin{array}{c}\text { LAZY } \\
100\end{array}$ & $\begin{array}{c}\text { LAZY } \\
95\end{array}$ & $\begin{array}{c}\text { LAZY } \\
90\end{array}$ & $\begin{array}{c}\text { LAZY } \\
85\end{array}$ & $\begin{array}{c}\text { LAZY } \\
80\end{array}$ & $\begin{array}{c}\text { LAZY } \\
75\end{array}$ & $\begin{array}{c}\text { FAITH } \\
\text { (strict) }\end{array}$ & $\begin{array}{c}\text { LAZY } \\
70\end{array}$ \\
\hline \hline a. rasgo & & & & & & $* !$ & & $*$ \\
\hline b. rasGo & & & & & & & $*$ & \\
\hline \hline Input: /futbol/ & & & & & & & & \\
\hline c. futbol & & & & & & & & $*$ \\
\hline d. futBol & & & & & & & $* !$ &
\end{tabular}

Dialects where spirantization applies even after a voiceless stop or a pause (Hualde 1990) require that FAITH(strict) be ranked below LAZY70. When FAITH(strict) only dominates effort thresholds below 70 effort units, the production of a voiced stop after another stop or a pause becomes too costly, $(34 b, f)$.

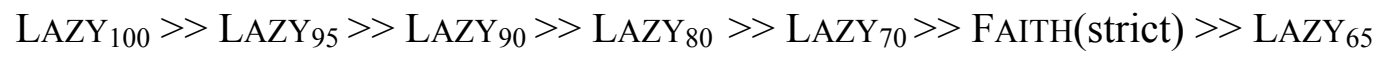

\begin{tabular}{c||c|c|c|c|c|c|c|c} 
Input: /futbol/ & $\begin{array}{c}\text { LAZY } \\
100\end{array}$ & $\begin{array}{c}\text { LAZY } \\
95\end{array}$ & $\begin{array}{c}\text { LAZY } \\
90\end{array}$ & $\begin{array}{c}\text { LAZY } \\
80\end{array}$ & $\begin{array}{c}\text { LAZY } \\
70\end{array}$ & $\begin{array}{c}\text { FAITH } \\
\text { (strict })\end{array}$ & $\begin{array}{c}\text { LAZY } \\
65\end{array}$ & $\begin{array}{c}\text { LAZY } \\
50\end{array}$ \\
\hline \hline a. futbol & & & & & $* !$ & & $*$ & $*$ \\
\hline b. futBol & & & & & & $*$ & & \\
\hline Input: /samba/ & & & & & & & & \\
\hline \hline c. samba & & & & & & & & $*$ \\
\hline d. samBa & & & & & & $* !$ & & $*$ \\
\hline \hline Input: /beso/ & & & & & & & & \\
\hline e. beso & & & & & $* !$ & & $*$ & $*$ \\
\hline f. Beso & & & & & & $*$ & &
\end{tabular}


The fact that there are no Spanish dialects where voiced stops spirantize after a nasal consonant is due to the maximal contribution in effort reduction made by nasals (35 effort units), plus the 15-unit bonus that comes with homorganicity since a nasal followed by another consonant always shares its place of articulation, unless speech is produced at unnaturally slow rates. Note that since the actual effort required to produce a voiced stop in post-nasal position is 50 units, spirantization does not represent a better alternative in this environment because the preceding nasal already brings the effort cost below the 70unit threshold. Consequently, there is no need to sacrifice the complete oral closure of the voiced stop, (34c).

This analysis not only handles all scenarios where voiced stops have been reported to spirantize in Spanish, but also captures the progression with which the process pervades from one dialect to another. The approach has been to shift the faithfulness constraint FAITH(strict) gradually down the LAZY hierarchy in the phonetic component to the effect that spirantization gains generality as lower effort thresholds overtake the faithfulness constraint that guards stricture specifications.

But so far we have been ignoring the fact that the segments that arise from spirantization may be either close fricatives, fricatives or approximants. Since the gist of spirantization is precisely to make voiced stops less effortful by loosening their oral closure, this issue is at the core of this process. The fact that spirantization may yield approximants as well as fricatives is not exclusive to Spanish. Giannelli and Savoia (1979) report that in Florentine Italian spirantization also gives rise to close fricatives, fricatives, and approximant sounds. The universal hierarchy of anti-effort constraints proposed in (25) suggests an explanation for the fact that there are languages in the world 
for which spirantization is not limited to changing stops into fricatives. Since a high degree of oral closure is the greatest impediment to voicing, approximants are better than fricatives in facilitating voicing.

$$
\text { LAZY(VdStop) }>\text { LAZY(VdClFric) }>>\text { LAZY(VdFric) })>\text { LAZY(VdAppr) }
$$

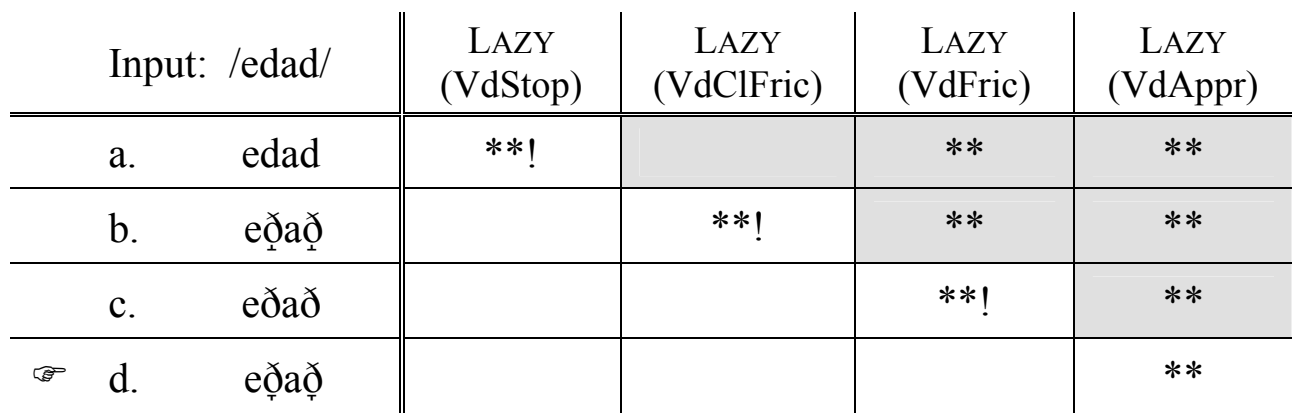

In tableau (35), the candidate that renders voiced stops into approximants, (35d), is selected as optimal because producing this kind of voiced segment is less effortful than articulating voiced stops, (35a), or either kind of voiced fricative, $(35 \mathrm{~b}, \mathrm{c})$. Furthermore, one must take into account that although nasals, liquids, and vocoids are also less effortful than voiced stops, spirantization does not give rise to such segments because that would require being unfaithful to features other than stricture (e.g. [nasal], [lateral], [consonantal], etc.).

(36) FAITH(nasal), FAITH(lateral), FAITH(conson) >> LAZY(Vdseg) >> FAITH(strict)

\begin{tabular}{cc||c|c|c|c|c}
\multicolumn{2}{c|}{ Input: $/$ kodo/ } & $\begin{array}{c}\text { FAITH } \\
\text { (nasal) }\end{array}$ & $\begin{array}{c}\text { FAITH } \\
\text { (lateral) }\end{array}$ & $\begin{array}{c}\text { FAITH } \\
\text { (consonantal) }\end{array}$ & $\begin{array}{c}\text { LAZY } \\
\text { (Vdseg) }\end{array}$ & $\begin{array}{c}\text { FAITH } \\
\text { (stricture) }\end{array}$ \\
\hline \hline a. & kodo & & & & $* * * * * * * * *$ & \\
\hline b. & kono & $* !$ & & & $* * * * * *$ & \\
\hline d. & koðָo & & & & $* * * *$ & $*$ \\
\hline e. & kolo & & $* !$ & & $* * * *$ & $*$ \\
\hline f. & koio & & & $* !$ & $* *$ & $*$
\end{tabular}


To save tableau space in the illustration of this point, I have compressed the constraints that form the universal anti-effort hierarchy for voiced segments into a single constraint, LAZY(Vdseg). Despite incurring fewer violations of LAZY(Vdseg), candidates (36d) and (36e) are discarded for being unfaithful to the features [nasal] and [lateral], which are more highly valued. Complete featural faithfulness, however, is not possible either because that would entail running afoul of all constraints on the anti-effort hierarchy, that is, nine violations of LAZY(Vdseg), (36a). An approximant allophone is optimal because it is less effortful than articulating a voiced stop and the only feature faithfulness constraint it violates is low-ranking FAITH(strict), (36d).

But this still leaves unexplained why approximants are not always the outcome of spirantization. One of the factors involved in determining whether the emerging spirant will be a closed fricative, fricative or approximant is the degree of constriction of the preceding segment. Closed fricatives (e.g. [alæָo] $</ a$ lgo/ 'something') and fricatives (e.g. $[\operatorname{ar} \beta \mathrm{ol}]</ \mathrm{arbol} /$ 'tree') are optimal correspondents for underlying voiced stops when the medial phase of the preceding segment involves some degree of constriction (e.g. [1], [r]), which makes it unnecessary to lose so much of the constriction of the voiced stop. By contrast, approximants are optimal (e.g. [laŗo] </lago/ 'lake') when the preceding segment has very little or no constriction at all (e.g. [a]), because that makes it necessary to relax the constriction of the voiced stop even further so that some effort may be actually saved. Consider these three possibilities in a dialect like Panamanian Spanish, where FAITH(strict) is dominated by effort thresholds of 85 units and above. 


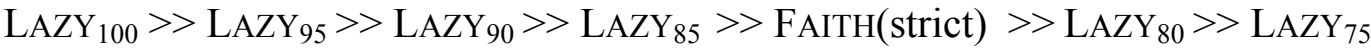

\begin{tabular}{|c|c|c|c|c|c|c|c|c|c|}
\hline \multicolumn{2}{|c|}{ Input: /lago/ } & $\begin{array}{c}\text { LAZY } \\
100\end{array}$ & $\begin{array}{c}\text { LAZY } \\
95\end{array}$ & $\begin{array}{c}\text { LAZY } \\
90\end{array}$ & $\begin{array}{c}\text { LAZY } \\
85\end{array}$ & $\begin{array}{l}\text { FAITH } \\
\text { (strict) }\end{array}$ & $\begin{array}{c}\text { LAZY } \\
80\end{array}$ & $\begin{array}{c}\text { LAZY } \\
75\end{array}$ & $\begin{array}{c}\text { LAZY } \\
50\end{array}$ \\
\hline a. & lago & $* !$ & $*$ & $*$ & $*$ & & $*$ & $*$ & $*$ \\
\hline b. & larxo & & $* !$ & $*$ & $*$ & $*$ & $*$ & $*$ & $*$ \\
\hline c. & laro & & & $* !$ & $*$ & $* *$ & $*$ & $*$ & $*$ \\
\hline d. & la & & & & & $* * *$ & & & $*$ \\
\hline
\end{tabular}

In tableau (37), the candidate that turns the underlying voiced stop into an approximant, (37d), rather than a fricative, (37d), or a close fricative, (37b), emerges victorious because it is the only one able to bring the effort required to produce the correspondent of the underlying voiced stop below the thresholds that dominate FAITH(strict). Note that for each degree of stricture that the complete oral closure is loosened; one violation of FAITH(strict) is scored. So, close fricatives violate FAITH(strict) only once because their constriction is immediately next to a complete oral closure, whereas fricatives violate this constraint twice because their degree of stricture is two levels below that of a voiced stop. Although providing an approximant as the output correspondent of an underlying voiced stop requires violating FAITH(strict) three times, this is the only way to invest less than 85 effort units without being unfaithful to features other than stricture.

By contrast, when the voiced stop is preceded by a segment whose medial phase involves some constriction, the complete oral closure of the voiced stop does not have to be loosened as much (38c). This is illustrated in the following tableau. 


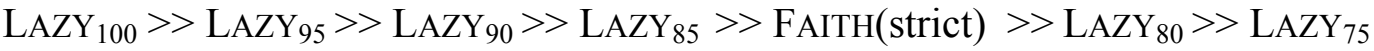

\begin{tabular}{|c|c|c|c|c|c|c|c|c|c|c|}
\hline & Input: & /arbol/ & $\begin{array}{c}\text { LAZY } \\
100 \\
\end{array}$ & $\begin{array}{c}\text { LAZY } \\
95 \\
\end{array}$ & $\begin{array}{c}\text { LAZY } \\
90 \\
\end{array}$ & $\begin{array}{c}\text { LAZY } \\
85 \\
\end{array}$ & $\begin{array}{l}\text { FAITH } \\
\text { (strict) } \\
\end{array}$ & $\begin{array}{c}\text { LAZY } \\
80 \\
\end{array}$ & $\begin{array}{c}\text { LAZY } \\
70 \\
\end{array}$ & $\begin{array}{c}\text { LAZY } \\
40 \\
\end{array}$ \\
\hline & a. & arbol & & & *! & $*$ & & $*$ & $*$ & $*$ \\
\hline & b. & $\operatorname{ar} \beta_{\perp} \mathrm{ol}$ & & & & *! & $*$ & $*$ & $*$ & $*$ \\
\hline 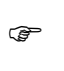 & c. & $\operatorname{ar} \beta o l$ & & & & & $* *$ & $*$ & $*$ & $*$ \\
\hline & d. & $\operatorname{ar} \beta_{\tau}$ ol & & & & & $* * * !$ & & & $*$ \\
\hline
\end{tabular}

In this case, candidate (38c) is the winner because a fricative allophone is enough to bring effort consumption below the 85 -unit threshold. Finally, if the medial phase of the preceding segment involves a greater degree of constriction, even less of the complete oral closure of the voiced stop needs to be given up, (39b), because a close fricative is enough to reduce effort below the crucial threshold.

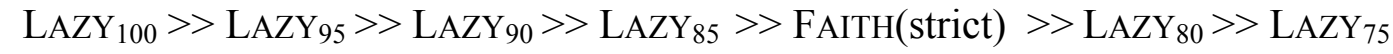

\begin{tabular}{|c|c|c|c|c|c|c|c|c|c|}
\hline \multicolumn{2}{|c|}{ Input: /algo/ } & $\begin{array}{c}\text { LAZY } \\
100 \\
\end{array}$ & $\begin{array}{c}\text { LAZY } \\
95 \\
\end{array}$ & $\begin{array}{c}\text { LAZY } \\
90 \\
\end{array}$ & $\begin{array}{c}\text { LAZY } \\
85 \\
\end{array}$ & $\begin{array}{l}\text { FAITH } \\
\text { (strict) }\end{array}$ & $\begin{array}{c}\text { LAZY } \\
80 \\
\end{array}$ & $\begin{array}{c}\text { LAZY } \\
75\end{array}$ & $\begin{array}{c}\text { LAZY } \\
30 \\
\end{array}$ \\
\hline a & algo & & & & $* !$ & & & & \\
\hline$\Leftrightarrow b$ & alŗo & & & & & $*$ & $*$ & & \\
\hline c & alro & & & & & $* * !$ & & $*$ & \\
\hline & al ָָo & & & & & $* * ! *$ & & & $*$ \\
\hline
\end{tabular}

In addition to the degree of constriction of the preceding segment, there is another factor that conditions the effort required to produce a voiced stop. At fast speech rates the production of any consonant requires an intensification of muscular effort. Fowler (1980:121) points out that whereas at a fast rate vowels become substantially shorter in duration by reducing the spatial coordinates of their targets, which serves to reduce muscular effort, consonants are slightly shorter in duration and are produced by 
increasing the force of the relevant muscles. As Fowler puts it "consonants could not be produced rapidly by decreasing muscle force, because their essential articulatory properties include obstructing or totally occluding the passage of air from the lungs. If the muscle forces which effect that consonantal obstruction were diminished, a different class of segment would be produced." To capture the actual effort required to produce voiced stops in connected speech at fast rates; an increment in effort must be added with every increase in speed. Following Harris (1969), I assume four speech rates: Largo, Andante, Allegreto, and Presto.

Four basic speech rates (Harris 1969:7)

Largo: $\quad$ Very slow. For example, trying to communicate with a foreigner who has little competence in the language.

Andante: $\quad$ Moderately slow. For example, delivering a lecture or teaching a class in a large hall without electronic amplification.

Allegretto: Moderately fast. In many situations one might easily alternate between Andante and Allegretto in mid-discourse or in mid-sentence.

Presto: $\quad$ Very fast.

In Largo, the effort required to produce a sound is close to producing that sound in isolation. For voiced stops, that would be close to our estimates in (24). Andante would correspond to our estimates of running, connected speech, (27). However, Allegretto and Presto represent rates where sounds must be articulated more rapidly, and 
for consonants, this may only be possible by intensifying muscular effort. I assume that articulating a voiced stop in Allegreto requires 10 effort units more than producing that consonant in Andante, whereas the same articulation requires 10 more effort units in Presto than in Allegretto (20 more than in Andante).

By taking rate into account, it is possible to provide an explanation for dialectinternal variation. Even if a dialect ranks the constraints $\operatorname{LAZY}(x)$ below FAITH(strict), spirantization may apply to a voiced stop in a context where the highest threshold that needs to be reached to produce the voiced stop is $x$, if the utterance containing that voiced stop is produced at a fast rate. This is because the increment in effort that is necessary to produce consonants at fast speed causes the threshold $x$ to rise (e.g. in Allegretto: $x+10$; whereas in Presto: $x+20$ ). As an example, consider the case of Bogotano Spanish, where spirantization has a high probability to apply after vocoids and glides but a considerably lower probability after consonantal segments (Amastae 1995). Despite the distinction that this dialect makes between consonantal and non-consonantal segments; at faster rates, spirantization may also apply after $/ \mathrm{r} /, / \mathrm{l} /$, or even $/ \mathrm{s} /$. Although we have established that in Bogotano Spanish, FAITH(strict) ranks below LAZY95, when speech is produced at Allegretto speed, spirantization may apply even after liquids because the estimated 90/85 effort units needed to produce a voiced stop after a rhotic/lateral become 100/95, which are thresholds above FAITH(strict). Tableau (41) maintains the same ranking established in (30) for Bogotano Spanish, but introduces "Alleg' to indicate the increased effort needed to produce the voiced stop at Allegretto speed. 


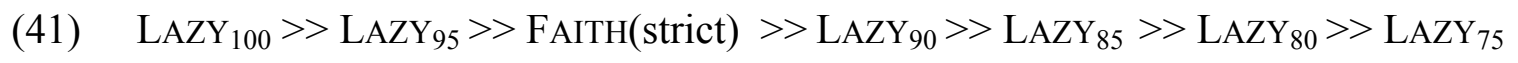

\begin{tabular}{c||c|c|c|c|c|c|c|c} 
Input: $/$ arbol/ & LAZY & LAZY & FAITH & LAZY & LAZY & LAZY & LAZY & LAZY \\
& 95 & (stric $)$ & 90 & 85 & 80 & 75 & 70 \\
\hline a. arbol & Alleg! & $*$ & & $*$ & $*$ & $*$ & $*$ & $*$ \\
\hline b. arBol & & & $*$ & & & & & \\
\hline Input: $/$ alba/ & & & & & & & & \\
\hline c. alba & & Alleg! & & $*$ & $*$ & $*$ & $*$ & $*$ \\
\hline d. alBa & & & $*$ & & & & &
\end{tabular}

At Presto speed, spirantization applies even to voiced stops that appear after [s], (42b), because the estimated 75 effort units that are needed to produce a voiced stop after a fricative consonant become 95 at this speed rate, which is a threshold ranked above FAITH(strict). In tableau (42), the constraint ranking is the same but 'Prest' is used to indicate the increase in effort required to produce a voiced stop in this context at this rate.

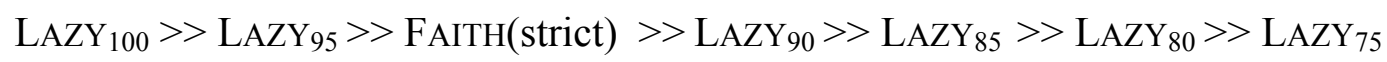

\begin{tabular}{cc||c|c|c|c|c|c|c|c}
\multicolumn{2}{l|}{ Input: $/$ desde/ } & $\begin{array}{c}\text { LAZY } \\
100\end{array}$ & $\begin{array}{c}\text { LAZY } \\
95\end{array}$ & $\begin{array}{c}\text { FAITH } \\
\text { (stric) }\end{array}$ & $\begin{array}{c}\text { LAZY } \\
90\end{array}$ & $\begin{array}{c}\text { LAZY } \\
85\end{array}$ & $\begin{array}{c}\text { LAZY } \\
80\end{array}$ & $\begin{array}{c}\text { LAZY } \\
75\end{array}$ & $\begin{array}{c}\text { LAZY } \\
70\end{array}$ \\
\hline a. desde & & Prest! & & $*$ & $*$ & $*$ & $*$ & $*$ \\
\hline b. & & & $*$ & & & & &
\end{tabular}

Rate is an active factor not only in causing dialect-internal variation but also in determining the degree of constriction of the allophone that emerges from spirantization. When the preceding segment has little or no constriction at all and speech is produced at a fast rate, an approximant emerges as the outcome of spirantization because this is the least effortful allophone to articulate. Tableau (43) shows that a voiced stop, (43a), 
which requires 100 effort units to articulate postvocalically in Andante, becomes exceedingly costly in Presto (120 effort units).

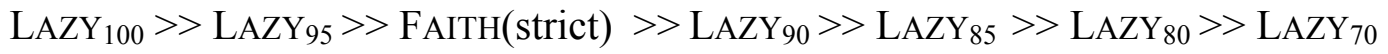

\begin{tabular}{|c|c|c|c|c|c|c|c|c|c|}
\hline \multicolumn{2}{|c|}{ Input: /lago/ } & $\begin{array}{c}\text { LAZY } \\
100+\end{array}$ & $\begin{array}{c}\text { LAZY } \\
100\end{array}$ & $\begin{array}{c}\text { LAZY } \\
95\end{array}$ & $\begin{array}{l}\text { FAITH } \\
\text { (stric) }\end{array}$ & $\begin{array}{c}\text { LAZY } \\
90\end{array}$ & $\begin{array}{c}\text { LAZY } \\
85\end{array}$ & $\begin{array}{c}\text { LAZY } \\
80\end{array}$ & $\begin{array}{c}\text { LAZY } \\
70\end{array}$ \\
\hline a. & lago & Prest! & $*$ & $*$ & & $*$ & $*$ & $*$ & $*$ \\
\hline b. & lą̧o & Prest! & $*$ & $*$ & & $*$ & $*$ & $*$ & $*$ \\
\hline c. & laro & & & Prest! & & $*$ & $*$ & $*$ & $*$ \\
\hline d. & ląָo & & & & & & & & Prest \\
\hline
\end{tabular}

Likewise, a voiced close fricative, (43b), which requires 90 effort units to articulate postvocalically in Andante, reaches the 110 effort threshold in Presto. Although a voiced fricative is not as effortful, it still requires 95 effort units, which is a threshold ranked above FAITH(strict) in the grammar of Bogotano Spanish. Because a voiced approximant, which requires an effort of 50 units to articulate postvocalically in Andante, keeps effort consumption acceptably low in Presto (70 effort units), it is selected as optimal, (43d). As the reader can infer, at the same rate, but preceded by segments endowed with various degrees of constriction such as $[\mathrm{r}]$ or $[\mathrm{s}]$, it is not necessary to lose so much of the oral closure of the underlying voiced stop; hence the fricative and the closed fricative allophones may be optimal.

Besides speech rate, register may also have an effect on spirantization given that lower registers tend to favor hypoarticulation. It is usually the case that in a high speech register, such as when the speaker is addressing someone of higher social status or someone who is not a member of her/his group, s/he strives to articulate as explicitly and clearly as possible so that the message can be understood. By contrast, in a lower 
register, such as when the speaker is addressing someone of equal or lower status or someone that $\mathrm{s} / \mathrm{he}$ identifies as a member of her/his group, the perceptual needs of the hearer fall second place to the articulatory ease of the speaker making hypoarticulation more likely to happen. Following Kirchner (1998), register effects may be captured by demoting FAITH(stricture) relative to the effort thresholds, which is formally equivalent to promoting the effort thresholds relative to FAITH(stricture). According to this, spirantization occurs more profusely in lower registers because a greater number of effort thresholds are allowed to surpass FAITH(stricture) as speech becomes more casual. In other words, the more informal the speech style, the less articulatory effort speakers make.

The analysis developed above accounts for both the cross-dialectal and dialect internal variation of spirantization through the same premises. Voiced stops are quite effortful and Spanish opts to make them less so by loosening their constriction. According to this, spirantization is a low-level process, as evinced by its gradiency, variability and rate and register dependence. This process is especially invigorated in the phonetic component, although Spanish also has some phonological spirantization, but limited to non-prominent linguistic positions, so that voiced stops may retain their distinctiveness in the phonological system. The results of this effort-reduction tendency vary depending on the degree of constriction of the preceding segment and the rate and register of speech, which are factors that bear directly on the amount of effort necessary to produce consonantal segments. A distinction has been made between markedness constraints and effort-reduction constraints. The former are phonetically grounded but active in the phonology, whereas the latter, although phonetically grounded, are limited 
to the phonetic component. Markedness constraints sanction the structural complexity of certain segments and have been shown to limit the Spanish obstruent inventory. It is because of their excessive markedness that Spanish does not have any voiced fricative/affricate phonemes.

On closing, I remark that this analysis argues against previous proposals that claim that Spanish has a voiced palatal fricative phoneme, $/ y /$, which surfaces as a voiced alveo-palatal affricate, [y̌], when preceded by a homorganic lateral, nasal or a pause, and as [y] elsewhere. In actuality, this segment is a palatal approximant, $/ \mathrm{j} /$, as it has been confirmed by phonetic studies such as Martínez-Celdrán (1984). Like other Spanish approximants, this segment is subject to a strengthening process that turns approximants into voiced obstruents. As the data in (44) show, strengthening gives rise to some voiced obstruents in Spanish. The input correspondents of these segments, however, are not voiced stops but sonorants that undergo this change in order to become more harmonious with the syllabic position they are assigned to (onsets). This follows from the fact that low-sonority segments are better suit to occupy the left edge of the syllable.

(44) Strengthening

\begin{tabular}{|c|c|c|c|}
\hline esa [j]abe & 'that key' & ese [w]eko & 'that hole' \\
\hline esas [j]abes & 'those keys' & esos [w]ekos & 'those holes' \\
\hline $\sin [y \check{y}] \mathrm{abes}$ & 'without keys' & $\sin \left[{ }^{\mathrm{w}}\right]$ ekos & 'without holes' \\
\hline tal [y̌]abe & 'such a key’ & tal $\left[{ }^{\mathrm{w}}\right]$ eko & 'such a hole' \\
\hline [y̌]abe & 'key’ & {$\left[{ }^{\mathrm{w}}\right]$ eko } & 'hole' \\
\hline
\end{tabular}


Whatever constraint is used to capture this effect (Bakovič (1996) proposes STRONGONSET), it must outrank the markedness constraint *VDCONTOBSTR in order to be able to force the emergence of voiced fricatives/affricates. I will not pursue this issue any further because a full account of this strengthening process falls beyond the scope of this paper.

\section{Conclusions and remarks}

The articulation of voiced obstruents requires an intensification of muscular effort in order to prevent the stoppage of transglottal airflow and subsequent inertia of the vocal folds. Relaxing the oral closure facilitates voicing, whereas failure to make any active muscular adjustments results in voicelessness. Due to the greater complexity of voiced obstruents, Spanish not only limits the number of segments of this class but also uses the processes of devoicing and spirantization to limit their occurrence. Phonologically, voiced obstruents are only allowed in linguistic prominent positions, but phonetically they may be avoided even there, unless they are aided by factors that promote articulatory ease. Within this frame, devoicing and spirantization are strategies used to reconcile the drive to preserve distinctive contrasts with the tendency to simplify linguistic structures in order to favor articulatory ease. Spanish also avoids obstruent segments whose articulation requires voicing and frication. The greater markedness of such segments arises from the antagonistic aerodynamic conditions that their articulation requires, which explains the existence of sound systems where voiced fricatives/affricates are absent, although voiced stops are tolerated. 
I have demonstrated that the aim of the processes of spirantization and devoicing is to reduce markedness and promote laziness. The apparent drive to make adjacent segments agree in feature values (assimilation) is just a side effect of effort reduction. The more similar in stricture the preceding segment is, the easier it is to reach the complete oral closure of a voiced stop. This effort-based approach has considerable advantages. It provides a principled explanation for the fact that, although endowed with a complete oral closure, Spanish voiceless stops do not tend to spirantize, and in the dialects where they do, they do not spirantize as often as voiced stops. This follows from the fact that although both stop series require a complete oral closure, voiced stops necessitate additional effort to maintain the vocal folds in motion. Because their articulation requires less effort, voiceless obstruents are a lesser priority to this effortreduction process. Another advantage of this approach is that it is not encumbered by a notion of directionality. While the assimilationist approaches are bound to a directionality parameter, this issue never arises in the effort-based approach because it does not assume that phonological features are spread. Whereas the assimilationist approaches fail to explain why a following [+continuant] segment does not trigger spirantization, the effortbased approach recognizes that in the orchestration of articulatory gestures, gesture overlapping is an efficient way to reduce articulatory effort. A context that supplies a preceding oral closure on which the voiced stop may lean is relevant in reducing the muscular effort necessary for its articulation. By contrast, the presence of constriction in a following segment makes no contribution to facilitating the achievement of the oral closure of the voiced stop because that gesture takes place after all phases of the voiced stop have already been implemented. Furthermore, because the analysis presented here 
relies on universal principles, it is able to unveil the connection between the processes of spirantization and devoicing, and it relates them to the fact that Spanish has such limited number of voiced obstruents in its sound inventory.

Unlike assimilationist accounts, this approach to spirantization easily handles the great deal of cross-dialectal and dialect internal variation attested throughout the Spanishspeaking world. By recognizing that Spanish dialects differ in the priority they assign to featural faithfulness vis-à-vis the drive to reduce effort, and that in addition to the stricture of the preceding segment, speech rate and register may also determine effort consumption, the analysis proposed here has an explanation for all attested patterns including the puzzling cases in which a voiced stop spirantizes after a pause or a voiceless stop, which escape all assymilationist accounts. Lastly, the neglected but crucial fact that spirants may be either close fricatives, fricatives or approximants has been brought to light and shown to be predictable and consistent with the forces that lie at the heart of this process. 


\section{References}

Alvarado de Ricord, Elsie. 1971. El español de Panamá, estudio fonético y fonológico. Panamá: Editorial Universitaria.

Amastae, Jon. 1989. The intersection of s-aspiration/deletion and spirantization in Honduran Spanish. Language Variation and Change, 1. 169-183.

Amastae, Jon. 1995. Variable spirantization: constraint weighting in three dialects. Hispanic Linguistics 6, 7. 265-285.

Bakovič, Eric. 1996. Strong onsets and Spanish fortition. Rutgers Optimality Archive, 96-0000.

Beckman, Jill N. 1996. Positional faithfulness. Doctoral dissertation, University of Massachusetts, Amherst.

Beckman, Jill N. 1999. Positional faithfulness. New York: Garland.

van den Berg, J. 1958. Myoelastic-aerodynamic theory of voice production. J. Speech Hear. Res. 1, 227-244.

Boyd-Bowman, Peter. 1955. Cómo obra la fonética infantil en la formación de los hipocorísticos. Nueva Revista de Filología Hispánica 9, 337-366.

Branstine, Zoann. 1991. Stop/spirant alternations in Spanish: on the representation of contrast. Studies in the Linguistic Sciences, 21. 1-22.

Carreira, María. 1998. A constraint-based approach to Spanish spirantization. In Leona, José and Esthela Treviño (eds.), Theoretical Analyses on Romance Linguistics: Selected Papers from the 26th LSRL. Amsterdam: John Benjamins. 143-157.

Féry, Caroline. 1998. Final devoicing and the stratification of the lexicon in German. Rutgers Optimality Archive 274-0798. 20 p. 
Fowler, Carol. 1980. Coarticulation and theories of extrinsic timing. Journal of Phonetics 8, 113-133.

Giannelli, L. And L. Savoia. 1979. Indebolimento consonantico in Toscana. Revista Italiana di Diallecttologia 2, 23-58.

Gnanadesikan, Amalia. 1997. Phonology with ternary scales. Doctoral dissertation. University of Massachusetts, Amherst.

Harris, James. 1969. Spanish phonology. Cambridge: MIT Press.

Harris, James. 1984. La espirantización en castellano y la representación fonológica autosegmental. Working Papers in Linguistics. Universitat Autonoma de Barcelona.

Henton, Caroline; Peter Ladefoged; and Ian Maddieson. 1992. Stops in the world's languages. Phonetica 49, 65-101.

Hualde, José Ignacio. 1988. A lexical phonology of Basque. Doctoral dissertation, University of Southern California, Los Angeles.

Hualde, José Ignacio. 1990. Consonantal rule interactions. Department of Spanish, Italian and Portuguese, University of Illinois at Urbana-Champaign, Ms.

Itô, Junko and Armin Mester. 1998. Markedness and word structure: OCP in Japanese. Ms. University of California at Santa Cruz.

Keating, Patricia. 1985. Universal phonetics and the organization of grammars. In Fromkin, Victoria (ed.), Phonetic Linguistics: Essays in Honor of Peter Ladefoged. Academic Press, Orlando, FL. 115-132.

Kirchner, Robert. 1994. Lenition in phonetically based Optimality Theory. Ms., Berkeley, CA. 
Kirchner, Robert. 1995. Contrastiveness is an epiphenomenon of constraint ranking. Rutgers Optimality Archive, 51-0295.

Kirchner, Robert. 1998. An effort-based approach to consonant lenition. Doctoral dissertation. University of California. Rutgers Optimality Archive, 276-0898. 354 p.

Laver, John. 1994. Principles of phonetics. Cambridge: Cambridge University Press.

Lipski, John. 1994. Spanish stops, spirants and glides: from consonantal to [vocalic]. In Mazzola, Michael (ed.), Issues and Theory in Romance Linguistics: Selected Papers from the 23th LSRL. Washington, D.C.: Georgetown University Press. 67-86.

Lisker, Leigh and Arthur S. Abramson. 1971. Distinctive features and laryngeal control. Language 47, 767-785.

Lombardi, Linda. 1996. Postlexical rules and teh status of privative features. Phonology $13.1,1-38$.

Lozano, María del Carmen. 1979. Stop and spirant alternations: fortition and spirantization processes in Spanish phonology. Doctoral dissertation, University of Indiana, Bloomington.

Maddieson, Ian. 1984. Patterns of sounds. Cambridge: Cambridge University Press. Martínez-Celdrán, Eugenio. 1984. Fonética. Barcelona: Editorial Teide.

Martínez-Gil, Fernando. 1992. The insert/delete parameter, redundancy rules, and neutralization processes in Spanish. In Fernando Martínez-Gil and Héctor Campos (eds.), Current Issues in Spanish Linguistics. Washington, D.C.: Georgetown University Press. 495-571.

Mascaró, Joan. 1984. Continuant spreading in Basque, Catalan and Spanish. In M. Aronoff and R.T. Oehrle (eds.) Language sound structure. Cambridge: MIT Press. 
Mascaró, Joan. 1991. Iberian spirantizatin and continuant spreading. In Albert Branchadell, Blanca Palmada, Josep Quer, et al. (eds.), Catalan Working Papers in Linguistics. Universitat Autonoma de Barcelona. 167-179.

McCarthy, John and Alan Prince. 1995. Faithfulness and reduplicative identity. University of Massachusetts Occasional Papers 18, 249-384.

Navarro Tomás, Tomás. 1967. Manual de pronunciación española. New York: Hafner.

Ohala, John. 1983. The origin of sound patterns in vocal tract constraints. In Peter MacNeilage (ed.), The production of speech. New York, NY: Springer-Verlag. 189216.

Pierrehumbert, Janet. 1980. The phonology and phonetics of English intonation. Ph.D. dissertation, Massachusetts Institute of Technology. Distributed 1987 by Indiana University Linguistics Club, Bloomington.

Piñeros, Carlos-Eduardo. 1999. Surface identity and ternary scales in Spanish voicing assimilation. Rutgers Optimality Archive, 370-1299. 38 p.

Prince, Alan and Paul Smolensky. 1993. Optimality theory: constraint interaction in generative grammar. Ms., Technical Report \# 2 of the Rutgers Center for Cognitive Science, Rutgers University.

Quilis, Antonio. 1981. Fonética acústica de la lengua española. Biblioteca Románica Hispánica. Madrid: Gredos.

Rubach, Jerzy. 1990. Final devoicing and cyclic syllabification in German. Linguistic Inquiry 21, 79-94.

Rubach, Jerzy. 1996. Nonsyllabic analysis of voice assimilation in Polish. Natural Language and Linguistic Theory 8, 427-463. 
Schmidt, P. 1926. Die Sprachfamilien und Sprachenkreise der Erde. Heidelberg.

Smolensky, Paul. 1995. On the internal structure of the constraint component Con of UG. Handout to talk presented at UCLA. Rutgers Optimality Archive, 86-0000.

Westbury, John. 1983. Enlargement of the supraglottal cavity and its relation to stop consonant voicing. Journal of the Acoustical Society of America 74, 1322-36.

Westbury, John and Patricia Keating. 1986. On the naturalness of stop consonant voicing. Journal of Linguistics 22, 145-166.

Widdison, Kirk A. 1997. Physical parameters behind the stop-spirant alternation in Spanish. Southwest Journal of Linguistics, 16. 73-84.

Zoll,Cheryl. 1998. Positional asymmetries and licensing. Expanded handout of a talk presented at the LSA meeting in New York City in January, 1998. 


\section{Notes}

I am indebted to the anonymous reviewers that provided me with valuable suggestions to improve this paper. All remaining errors are my mine.

1 This inventory does not include the voiceless interdental fricative $/ \theta /$, which is absent from Latin American dialects.

2 I have adopted the IPA symbols for raising and lowering to differentiate close fricatives and approximants from regular fricatives.

3 This formulation of the constraint assumes that the feature [voice] is privative. Should it be demonstrated that [voice] is a binary feature, as defended by authors such as Rubach $(1990,1996)$ and Lombardi (1996), or scalar as proposed by Gnanadesikan (1997), the constraint may be easily adjusted to include the appropriate feature value.

$4 \quad$ The principle that forces certain voiced stops to have unfaithful output correspondents even when parsed as syllable onsets belongs to the phonetic component and is revealed in Section 7.

$5 \quad$ Alternative analyses of syllable-final devoicing have been developed within Optimality Theory. Féry 1999 uses a Positional Markedness approach to account for final devoicing in German. However, she still needs to use Positional Faithfulness to account for some of the data and is forced to conclude that both Positional Markedness and Positional Faithfulness are necessary. This is also the conclusion reached by Zoll (1998), who identifies several patterns that may only be handled by Positional Markedness. Within the model assumed here, (see 4), both types of positional constraints have a place in the grammar. Positional Faithfulness arises from the phonology, where faithfulness to distinctive contrasts takes precedence, whereas Positional Markedness emerges from the phonetics, where the main drive is to minimize articulatory effort. A third approach to syllable-final devoicing is Local Constraint Conjunction (Itô and Mester 1998), which is less restrictive because there is no limit to the number of constraints that can be conjoined, whereas both Positional Faithfulness and Positional Markedness benefit from the fact that there is a limited number of linguistic prominent positions.

6 In regards to stops, I am ignoring the fact that anterior stops impede voicing to a lesser sub-degree than posterior ones. This is due to the fact that the further front the constriction, the more expandable vocal 
wall area there is between the glottis and the constriction. As a result of this, transglottal airflow may be maintained longer in anterior stops (Lisker and Abramson 1971, Westbury 1983, Keating 1985, Hayes 1996). The reason why I am ignoring this variable is because Spanish spirantization is totally irreverent of anterior points of articulation, suggesting that in this language, pressure actuated enlargement of the supraglottal cavity is not exploited. This, however, awaits confirmation by empirical studies.

7 It is for future research to reveal with physical measurements the real effort thresholds for voicing. For now I rely on the assumption that the continuum of voicing effort thresholds rises proportionally to the degree of constriction. 